\title{
Beobachtungen und Versuche am suspendirten Herzen.
}

\author{
Zweite Abhandlung. \\ Ueber die Leitung der Bewegungsreize im Herzen. \\ Von \\ Th. W. Engelmann \\ in Utrecht. \\ Hierzu Tafel IX u. X.
}

\section{Einleitung.}

Die Physiologie des Herzens erfährt in nevester Zeit eine Umgestaltung, welche weit über ihr nächstes Gebiet hinaus eine Umwandlung in der Auffassung fundamentaler Lebenserscheinungen hervorzubringen verspricht. Es wankt - und fällt wie es scheint - die alte Lebre, welche in dem eigenen Nervensystem des Herzens die Quelle der selbständigen Herzthätigkeit und den Vermittler des Herzrhythmus erblickt.

Zur Zeit ibrer Aufstellung und ersten Ausbildung, vor etwa einem halben Jahrhundert, durfte diese Lehre wohl begründet heissen. Kein geringerer als $\mathrm{J}_{0} \mathrm{~h}$ a $\mathrm{n} \mathbf{n}$ es $\mathrm{M}$ i⿱ 11 e $\mathrm{r}^{1}$ ) steht unter ihren Urhebern obenan. Neben und nach ihm haben A. W. Volkmann und F. H. Bidde ${ }^{2}$ ) das Meiste zu ibrer Begründung und Ein-

1) Joh. M ü 11 e r, Handbuch der Physiolologie. Bd. T. 1834. p. 612 ff; p. 719 ff,, vgl. auch p. 711 . - Bd. II. 1837 p. $66-73$, auch p. 51-52.

2) F. H. Bidder und A. W. Vo $1 \mathrm{kmann}$, die Selbständigkeit des sympathischen Nervensystems durch anat. Unters. nachgewiesen. Leipzig 1842. A. W. Volkman n, Artikel Nervenphysiologie in Rud. Wagner's. Hand- 
bürgerung beigetragen. Ihre Berechtigung sehöpfte diese Lehre bauptsächlich aus folgenden Thatsachen und Erwägungen.

Seit alter Zeit wusste man, dass das Herz eigene Nervengeflechte besitzt, deren Fasern sich wenigstens zum Theil in der Muskelsubstanz verlieren. Die Muskelfasern des Herzens waren als quergestreift erkannt und damit den gewöhnlichen willkuirlichen Muskelelementen in dem anseheinend wichtigssten Punkte gleich. Muskelfasern zogen sich, soviel man damals wusste, unter normalen Bedingungen nur infolge Erregung ihres Nerven zusammen. Die vom Hirn und Rückenmark zum Herzen tretenden Nervenstämme, welche namhafte Physiologen für die Erreger der Herzbewegungen gehalten hatten, konnten dies nicht sein, da auch das ausgeschnittene Herz noch regelmässig und in normalem Rhythmus klopfte. Den im Herzen selbst verlaufenden Nervenstämmen durfte man das Vermögen nicht zuschreiben, automatisch die Herzmuskulatur in periodische Thätigkeit zu bring'en, da motorische Nervenfasern unter den im Körper gegebenen Bedingungen nur von den nervösen Centralorganen aus in Erregung versetzt werden. Die Beweise für eine centrale Function auch der peripherischen, in den Organen des vegetativen Lebens eingebetteten Ganglien, eine Function, die schon $\mathrm{Bichat}$ behauptet hatte, mehrten sich durch anatomische und physiologische Beobachtangen ${ }^{1}$ ). In den Athembewegungen hatte man einen Fall ähnlich regelmässiger periodiseher Bewegungen, unzweifelhaft hervorgerufen durch, anscheinend automatische, Erregung von Nervencentren (noeud vital). Johannes Müller ${ }^{2}$ ) hatte wiederholt dureh Betupfen des Ganglion coeliacum mit Kali causticum die erlöschenden Bewegungen des Kaninchendarms zu neuer Energie anfachen können. Die motorische Function eines peripherischen sympathischen Ganglion schien hiermit direkt erwiesen.

wörterbuch der Physiologie. II. Bd. 1844. p. 476, besonders p. $606 \mathrm{ff}$, p $616 \mathrm{ff}$. Auch : Müller's Archiv. 1844. p. 359.

1) F. H. Bidder und A. W. Volk mann, 1. c. - A. Köliker, Die Selbständigkeit und Abhängigkeit des sympathischen Nervensystems. Zürich 1845. - A. W. Volk m a $\mathrm{n}$, Art. Nervenphysiologie in R ud. Wagner's Handwörterbuch II. p. $476 \mathrm{ff}$.

2) J o b. M ü 11 e r, Handwörterbuch d. Physiol, Bd. I. 1834. p. 711 II. 1837. p. $68 \mathrm{ff}$. 


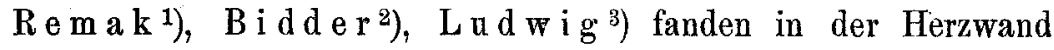
eine Fülle von Ganglien, deren Zellen als Ursprungstätten von Nervenfasern erkannt wurden. Nichts lag näher, als in diesen Ganglien die Centren für die Erzeugung der normalen Bewegung:santriebe des Herzens zu erblicken.

Die allgemeinen, coordinirten Beweg'ungen, welche bei künstlicber Reizung des Herzens auftreten, durften als Reflexbewegungen, ein Theil der Herzganglien als Reflexcentra betrachtet werden. Die regelmässige, durch Nerven und centrale graue Substanz vermittelte Peristaltik der beim Schlingakt betheiligten Muskulatur war ein Beispiel associirter Reflexbewegungen, das die mannichfachste Aehnlichkeit mit der Herzperistaltik bot: wie mechanische Reizung der Schleimhaut den Schlingakt, so löste Reizung des Herzens, namentlich des Endocards, eine Pulsation des ganzen Organs aus, von der einflussreiche Autoren ${ }^{4}$ ) behaupteten, dass sie, gleichviel ob man Kammern oder Vorkammern reize, stets an den Vorkammeru beginne, um sich von hier nach den Ventrikeln fortzupflanzen.

An den Einmündungsstellen der grossen Hoblvenen, wo schon nach alten, seitdem oft bestätigten Beobachtungen, die Contraction des Herzens jedesmal ibren Ausgang nimmt, wies $\mathrm{R}$ e $\mathrm{m}$ a $\mathrm{k}$ besonders mächtige Ganglienzellenhaufen nach. St a $\mathbf{n} n$ i u s ${ }^{5}$ ) zeigte, dass nach Abbinden des Herzens zwischen diesen Zellhaufen und den Vorkammern Atrien und Ventrikel beim Frosche stillstehen, der ganglienhaltige Venensinus aber weiterklopft. Doch zogen sich Vorkammern und Kammern noch bei kïnstlicher Reizung zusammen und begannen beide bei Ligatur oder Durchschneidungen an der Kammergrenze wieder zu pulsiren. Dies erforderte auf dem Boden jener Lehre die Annahme eigener, mit Reflexvermögen und Automatie begabter Nervencentren in der Wand der Kammern

1) R. Re m a k, Ueber die Ganglien des Herzens. Müll. Archiv 1844. p. 463. Auch schon in Froriep's Notitzen 1838. p. 137.

2) F. H. Bid d e r, Briefl. Mittheilung an A. W. Volkmann, Rud. Wagner's Handwört. II 1844. S. 497. - Müller's Arch. 1852. p. 163.

3) C. Lu d wig, Ueber die Herznerven des Frosches. M üll le r's Arch.1848. p. 139, Taf. V.

4) K ür s chne r, Art. Herzthätigkeit in Rud. Wagner's Handwörterbuch. Bd. II. 1844. p. 73. - B ud g e, Art. Sympathischer Nerv, mit besonderer Rücksicht auf die Herzbewegung. ibid. Bd. III. 1846. p. 425.

5) Stannius, Zwei Reihen physiologischer Versuche. Rostock 1851. Auch Müllers Archiv. 1852. p. 85 . 
und Vorkammern. Als solehe sehienen die von L u d w i g im Septum atriorum und die von $B$ idder und Rosen berger ${ }^{1}$ ) an der Kammergrenze, in der Valvula atrioventricularis aufgefundenen Zellhaufen angesprochen werden zu dürfen. Nach Abschneiden der Kammerbasis stand die nunmehr ganglienlose "Herzspitze" dauernd still.

Ohne die Annahme einer Vermittlung durch Ganglienzellen sehien auch das relativ lange Intervall zwischen den Zusammenziehungen je zweier aufeinanderfolgender Herzabtheilungen schwer verständlich. Die offenbare Verzögerung der Reizleitung an der Grenze zweier Herzabschnitte war nur natürlich bei Annabme der

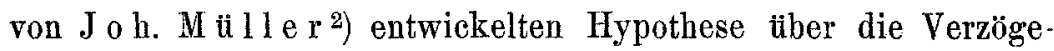
rung der Leitung des Nervenprincips in den sympathisehen Ganglien. Und sie wurde es mit noch viel mehr Grund, als v. Hel m. $\mathrm{h} 0 \mathrm{t} \mathrm{z}^{3}$ ) die vergleichsweise ausserordentliche Langsamkeit der Reizübertragung in der grauen Substanz des Rückenmarks experimentell nachgewiesen hatte.

Inzwischen waren auch in der Wand anderer, periodischperistaltisch sich bewegender Organe (Darmkanal, Blase, Ureter, Uterus) Nervengeflechte mit Ganglienknoten gefunden ( $\mathrm{R} \mathrm{e} \mathrm{mak}$, A u e rbach, Meis.sner a. a.)

Dazu kam dann die Entdeckung der Hemmungswirkung des Vagus (E d. W e b e r $\left.{ }^{4}\right), B$ u d g e ${ }^{5}$ ), später die der Acceleratoren (v. Bezold $d^{6}$ ). Für solche Wirkungen hatte man bis dahin nur in hemmenden und beschleunigenden Nerveneinflüssen auf centrale grane Substanz (Athemcentrum, motorische Centra im verlängerten Mark

1) Gust. Rosenberger, De centris motuum cordis. Diss. inang. Dorpati Liv. 1850.

2) Joh. M ï 11 e r, Handbuch des Physiol. II. 1837. p. 79-73.

3) $\mathrm{H}$. H e I m holtz, Ueber die Geschwindigkeit einiger Vorgänge in Muskeln und Nerven. Monatsber. der Ak. d. Wissensch. zu Berlin. 15. Juni 1855.

4) Omodei, Annali universali di medicina. Vol. CXVI. Nov. 1845. p. 225. Ed. W e b e r, Artikel Mrskelbewegung, Rud. Wagner's Hardwörterb. d. Physiol. III. Zweite Abth. 1846. p. $42 \mathrm{~A}$.

5) J. B u d g e, Die Abhängigkeit der Herzbewegungen vom Rïckenmark und Gehirn. Roser und Wunderlich's Archiv, 1846. p. 319 u. 540.

6) A. v on $\mathrm{B}$ e z old, Untersuchungen über die Innervation des Herzens. 2. Abtheil. Ueber ein neues „excitirendes" Herznervensystem im Gehirn und Rückenmark der Säugthiere. Leipzig. 1863. 
und Rückenmark) Analogien, nicht aber in direkten Wirkungen von Nerven auf ganglienfreie Mụskelmassen. Erhöhten Grund einen sehr komplizirten Nervenmechanismus im Herzen anzunehmen, lieferte der Nachweis der unerwarteten Complication jener Nerveneinflüsse, die nicht, wie man anfangs glaubte, nur das Tempo, sondern auch die Kraft und den Umfang der Herzbewegungen (Co a t ${ }^{1}$ ), $\mathrm{N}$ a e $\mathrm{l}^{2}$ ), $\mathrm{H}$ e i d e $\left.\mathrm{n} \mathrm{ha} \mathrm{i}{ }^{3}\right)$ ) ja nach neuerenAngaben (G a s kell ${ }^{4}$ ), M e. W ill i a ${ }^{5}{ }^{5}$ ) auch das Leitungsvermögen der Herzwand für die motorischen Impulse abändern, und deren Ineinandergreifen, wie u. a. die Erfolge gleichzeitiger Reizung des Vagus und der Acceleratoren lehren ( $\mathrm{L} \mathfrak{d} \mathrm{d}$ i g and $\mathrm{Bax} \mathrm{t}^{6}$ ), nachdrïcklich auf räumlich verschiedene nervöse Angriffspunkte im Herzen weist.

Im selben Sinne sprachen endlich auch die mannichfachen höchst auffälligen Wirkungen von Giften auf das Herz, denen bei gewöhnlichen ganglienfreien Muskeln kaum, wohl aber bei nervösen Centralorganen verwandte Wirkungen zar Seite gestellt werden konnten.

Dieses scheinbar so wohlgefügte Lehrgebände ist nun mehr und mehr wankend geworden. Zwar hatten hervorragende Forscher immer wieder an den hypothetischen Charakter seiner Grundlagen erinnert für die grosse Masse war wie üblich die Hypothese zum Dogma, das Dogma zum Axiom geworden.

Mit dem Nachweise ${ }^{7}$ ), dass die periodischen Bewegungen des Ureter im entwickelten Thiere einer automatischen Erregbarkeit der Muskelfasern, nicht aber Ganglien ihren Ursprung dan-

1) J. Coats, Wie ändern sich durch die Erregung des Nv. vagus die Arbeit und die innern Reize des Herzens? Ber. d. k, sächs. Ges. der Wiss. Leipzig. 1869. Dezember.

2) $\mathrm{Nael}$, Over den invloed van vagusprikkeling op de hartscontracties by den kikvorsch. Onderzoek. physiol. lab. Utrecht. (3) II. 1873. p. 91.

3) R. $\mathrm{H}$ e i d e $\mathrm{n}$ a i n, Untersuchungen über den Einfluss des Nv. vagus auf die Herzthätigkeit. Dies Archiv. Bd. XXVII. 1882. p. 383.

4) W. H. Gaske11, On the rhyten of the heart etc. Philos Trans. vol. CLXXIII. p. 993. 22. Dec 1881.

5) J. A. Mc. William, On the phenomena of inhibition in the mammalien heart. Journal of Physiology IX. 1888. p. 345 flg.

6) N. B axt, Ueber die Stellung des N. vagus zum N. accelerans cordis. Arbeit. des physiol. Instit. zu Leipzig 1875.

7) Th. W.E. Zur Physiologie des Ureters. Dies Archiv. II. 1869. p. 279 ff. 
ken, wurde wohl zuerst die Nothwendigkeit hinfällig, für die Erklärung rhythmischer Muskelcontractionen immer zunächst nach Ganglienzellen zu suchen. Die damals ${ }^{1}$ ) ausgesprochene Vermathang, dass auch die normalen Herzpulsationen beim Erwachsenen vielleicht rein muskulären Ursprung haben möchten, wurde denn anch bald insoweit gestiutzt, als es sich zeigte, dass wenigstens ein Theil der entwickelten Herzmuskulatur (Bulbus arteriosus vom Froseh) ${ }^{2}$ ) ohne Mitwirkung von Ganglien schon unter den normalen nahezu gleichen Bedingungen automatische Reizbarkeit besitzt, andere ganglienfreie Abschnitte (die „Herzspitze") wenigstens unter gewissen Bedingungen durch allerhand Einflüsse leicht in lang anhaltendes Pulsiren gerathen können ${ }^{3}$ ). Ja, es fand sich ${ }^{4}$ ), dass sogar gewöhnliche quergestreifte Muskeln, durch Curare des Nerveneinflusses beraubt, in gewissen Salzlösungen in rhythmische Thätigkeit zu gerathen vermögen.

Erschien trotz aller dieser neuen Ermittelungen der muskuläre Ursprung der normalen Bewegungsreize des Herzens immerhin nur erst als eine Möglichkeit, welche weitere Prüfung verdiente, so war inzwischen die Hypothese rom reflectorischen Charakter der durch künstliche Reizung der Herzwand hervorgerufenen Bewegungen direct widerlegt worden.

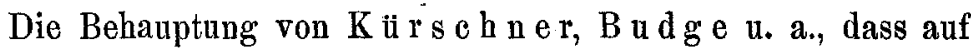
jede wo immer angebrachte Reizung des Herzens stets der Vorhof sich zuerst contrahire, war trotz des besonderen Nachdrucks, mit dem sie ausgesprochen worden war, unrichtig erfunden worden. Die besten Beobachter sahen die Contraction immer in der direct gereizten Abtheilung des Herzens beginnen. Die Angaben Paglia$\mathrm{n}$ is ${ }^{5}$ ), der durch Reizung ausschliesslich sensibler Nerven der

1) a. a. 0. p. 292.

2) Der Bulbus aortae des Froschherzens. Dies Archiv. XXIX. 1882. p. 425 .

3) C. Eckhard (galvanischer Strom), C. Ludwig mit Bowditch, Merunowicz, Stiénon u. a., Gaskell (chemische und méchanische Einflüsse) und viele andere Angaben.

4) W. Biedermann, Ueber rhythmische durch chemische Reizung bedingte Contractionen quergestreifter Muskeln. Sitzungsber. d. Wiener Ak. 3. Abth. LXXXII. p. 257. 1880:

5) $\mathrm{P}$ a g 1 i a n'i , Ueber die Funktion der Herzganglien. Moleschott's Untersuchungen zur Naturlehre XI. 1874. p. 364. 
Häute des Herzens reflectorische Bewegung hervorgerufen haben wollte, konnten gleichfalls nicht bestätigt werden. Bedingung für das Zustandekommen einer Pulsation war immer, dass die Muskelsubstanz direct erregt wurde. Die von älteren und neweren Beobachtern hervorgehobene grössere Reizbarkeit des Herzens von der inneren Oberfläche aus konnte sehr wohl auf einer grösseren Reizbarkeit der zunächst unter dem Endocard liegenden Fasern. erklärt werden. Mussten doch schon die im Verhältniss zu der der Muskelfasern der äusseren Oberfläche des Herzens mehrgeschïtzte Lage und die grössere Oberflächenentwicklung in diesem Sinne wirken. Auch legt das Vorkommen der P u rk in je s e he n Muskelfasern unter dem Endocard den Gedanken an spe e if is ch e Unterschiede der Muskelerregbarkeit im Herzen nahe. Bei Zerschneiden der Herzkammer in beliebige Stiicke verhielt sich jedes Stück künstlichen Reizen gegenüber wesentlich wie die unversebrte Kammer: stets hatte ein Reiz entweder keine oder eine maximale

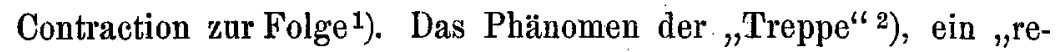
fractäres" Stadium ${ }^{3}$ ), die Unmöglichkeit anders als periodisch sich zu contrahiren ${ }^{4}$ ) sind stets nachweisbar, oft selbst an mikroskopisch kleinen Muskelstïckchen, bei denen sich die Abwesenheit von Ganglienzellen mit voller Gewissheit constatiren lässt.

Es liess sich weiter zeigen, dass die Erregung sich im Herzen vom Ort des Reizes aus nach allen Richtungen bin durch die Muskelsubstanz ausbreitet und zwar so, als ob jede als ein einheitliches Ganzes sich bewegende Herzabtheilung eine einzige hohle Muskelfaser sei ${ }^{5}$ ).

1) H. P. B ow ditch, Ueber die Eigenthümlichkeiten der Reizbarkeit, welche die Muskelfasern des Herzens zeigen. Arbeit. aus der physiol. Anstalt zu Leipzig 1871. p. 139.

2) Ebenda.

3) E. -J. Marey, Des mouvements que produit la coeur lorsqu'il est soumis à des excitations artificielles. Comptes rendus. LXXXII. 1876. p. 408.

4) L: Ra n vi er, Leģons d'anat, générale. Année 1877-78. Paris 1880. p. 41 etc.

5) A d. Fick, Sitzungsber. d. phys.-med. Ges. zu Würzburg. Sitz. vom 13. Juni 1874. - Th. W. Engelmann, Ueber die Leitung der Erregung im Herzmuskel. Proc. verb. k. Akad. v. wet. Amsterd. Verg. v. 16. Dez. 1874. - Dies Archiv XI. 1875. p. 465. - Die F i ck'schen Beobachtungen, in keinem Jahresbericht citirt, nur kurz an ziemlich verstecktèr Stelle 
An dem durch Zickzackschnitte beliebig gespaltenen Ventrikel konnte sich die Contraction von jedem Stïck nach jedem anderen fortpflanzen. Dies war unmöglich durch einen Nervenmechanismus zu erklären, sondern nur durch Mittheilung der Erregung direct von Muskelzelle auf Muskelzelle, nach dem zuerst für Flimmerepithelien ${ }^{1}$ ), dann für glatte Muskeln ${ }^{2}$ ) and Nervenfasern son mir anfgestellten Princip der Leitung durch Zellcontact. Eine anatomische Berechtigung fand diese Erklärung in der inzwischen erlangten Einsicht ${ }^{3}$ ), dass die Elemente der Herzmuskulatur nicht, wie man früher meinte, verzweigte, von eigener Membran umschlossene vielkernige Muskelfasern, sondern membranlose, kettenartig aneinandergefügte einkernige Zellen sind. Mit Nervenleitung unvereinbar war auch die sehr geringe, nur nach Millimetern statt nach Metern zu bemessende Geschwindigkeit, mit welcher man in jenen Schnittversuchen die Contraction durch die Herzmuskulatur fortschreiten sah.

$\mathrm{Zu}$ gleichem Resultate führten Versuehe ${ }^{4}$ ) über die Fortpflanzung der electrischen Reizwelle in der Kammer. Bei künstlicher Erregung ward stets die direct gereizte Stelle zuerst negativ electrisch und diese Negativität breitete sich von hier wellenförmig mit derselben geringen Geschwindigkeit wie die Contractionswelle in allen Richtungen über die Kammermuskulatur aus. - Bei der von den Vorhöfen ausgehenden Erregung wurde im Allgemeinen zuerst die Basis des Ventrikels negativ electrisch, wo ja anch nachweislich die Contraction beginnt.

Hiermit schienen die Bewegungen jeder einzelnen Herzabtheilung für sich wohl verständlich in der Voraussetzung, dass die

veröffentlicht, sind mir erst später durch Prof. C. L u dwig bekannt geworden.

1) Ueber die Flimmerbewegung. Leipzig. 1868. p. 155.

2) Zur Physiologie des Ureter. Dies Archiv II. 1869. p. 273 ff. - Ueber die peristaltische Bewegung, insbesondere des Darms. Ibid. IV. 1870. p. 33.

3) A ug. Weisma $\mathbf{n}$, Ueber die Muskulatur des Herzens beim Menschen und in der Thierreihe. Arch. f. Anat. u. Physiol. 1861. p. 42.

4) R. M a r c h a n d, Beiträge zur Kenntn. der Reizwelle u. Contractionswelle im Herzen. Dies Arch. XV. 1877. p. 511. - Th. W. Enge l ma n n, Over de electrische: verschynselen die de contractie von het hart vergezellen. Proc. verb. k. Akad, v. Wet. te Amsterd. 24. Nov. 1877. Ausführlich: Dies Archiv XVII. 1878. p. 68. 
Muskelfasern selbst Erzeuger und Leiter der Erregung seien. Schwer erklärlich blieb aber die langsame Uebertragung der Erregung von einem Herzabschnitt auf den nächstfolgenden, schwer verständlich auch der Einfluss der cerebrospinalen und sympathischen Nerven auf das Herz.

Der letztere Punkt sei hier nur kurz berïhrt. Schon die Entdeckung, dass Vagusreizung den Umfang und die Kraft der Vorhofsystole, ja auch der Kanmersystole ohne gleichzeitige Aenderung der Schlagfrequenz bis fast zum völligen Verschwinden schwächen können, scheint mir den Beweis zu liefern, dass es sich hier um eine directe Einwirkung der Nerven auf die Maskelsubstanz handelt. Und ebenso bei der entgegengesetzten Wirkung der schlagverstärkenden Fasern. Bei künstlicher, nicht übermaximaler Reizung der Herzmuskelfasern sind Qualität und Stärke des Reizes bekanntlich ohne deutlichen Einfluss auf Umfang und Kraft der Pulsation. Es scheint deshalb nicht erlaubt, ohne weitere Beweise anzunehmen, dass durch eine Aenderung natirlicher, der herrschenden Voraussetzung zufolge von Nerven kommender Reize jene Grössen geändert werden können. Die Muskelsubstanz selbst, ihr C o n tra cti o n s vermögen, muss sich geändert haben. Und diese Annahme ist um so mehr erlaubt, als ja auch künstliche Reize während des Bestehens jenes Nerveneinflusses immer stärkeren bezüglich schwächeren Erfolg als in der Norm haben ${ }^{1}$ ).

Den umfangreichsten and werthvollsten Versuch, die in dem Einfluss der Herznerven gelegenen Schwierigkeiten zu beseitigen, danken wir W. H. Ga s k el12). Seine umfassenden Untersuchungen, aus denen hier nur die fundamentale Entdeckung der die Hemmungserscheinungen begleitenden electrischen Vorgänge noch besonders hervorgehoben sei ${ }^{3}$ ), führen zu dem Schlusse, dass beim Herzen eine directe, doppelte und entgegengesetzte, an verschiedene Nervenfasern gebundene Einwirkung auf die Muskelsubstanz

1) Coats a. a. 0 .

2) Ein Auszug der in zahlreichen Publikationen niedergelegten Arbeiten - Gaskell's, mit Angabe des Orts der Veröffentlichung, findet sich von der Hand des Autors in den Archives de physiol. norm. et pathol, vom 1. Jan. 1888. p. $56-68$.

3) W. H. Gaske 11, Ueber die elektrischen Veränderungen, welche in dem ruhenden Herzmuskel die Reizung des Nervus vagus begleiten. Beitr. zur Physiologie. Zu C. L udw ig's 70. Geburtstag. Leipzig 1886 p. 114. 
besteht, die Gaskell als anabolische und katabolische unterscheidet und die mutatis mutandis auch bei den Muskelfasern der Blutgefässe (Constriction und Dilatation) und anderer Organe des vegetativen Lebens, ja vielleicht bei allen dem Nerveneinfluss unterworfenen Gewebselementen besteht.

Ich wende mich hier im Besonderen der Frage zu nach dem Mechan ismus, durch welehender motorische Reiz durch eine Herzabtheilung auf die nächstfolgendefortgeleitet wird.

Auf Grund der älteren anatomischen Untersuchungen nahm man bis vor Kurzem an, dass jede der als ein Ganzes sich bewegenden Abtheilungen des Herzens ein völlig abgeschlossenes Muskelfasersystem besitze. Muskelbrücken zwischen den einzelnen Abtheilungen sollten fehlen, während Nervenverbindungen selbst ziemlich grober Art längst nachgewiesen waren. Inzwischen zeigte Paladin $0^{1}$ ) in einer ausgedehnten Untersuchung, dass beim Menschen and den verschiedensten Wirbelthieren Muskelbündel vom Vorhof in die Kammern treten. Dasselbe fand Gaskell2) für den Frosch und die Schildkröte. Neuere Bestätigungen für andere Vertebraten kamen durch A. F. Stanley Kent ${ }^{3}$ ) and W. $\mathrm{H}$ i s jr. ${ }^{4}$ ).

Die wichtige Thatsache ist an einem in frontale Serienschnitte zerlegten Herzen des Frosches ohne jede Mühe zu constatiren. Eine schon mit der Lupe leicht kenntliche dicke Muskelcommissur besteht hier zwischen Vorkammern und Kammer in der Mitte der Basis in der Gegend des Ansatzes der Vorkammerscheidewand. Sowohl rom rechten wie vom linken Atrium strahlen Muskelfaserbündel in den Ventrikel ein. Ich kann hinzufügen, dass auch eine ziemlich dicke Muskelbrücke vom Ventrikel nach dem Bulbus arteriosus und vom Sinus nach den Atrien führt. Die

1) G. Paladino, Contribuzione all' anatomia, istologia e fisiologia del cuore. Napoli 1876.

2) W. H. Gaskell, Brit. Med. Journ. 1882. Vol. II. p. 572 und Journ. of Physiology IV. 1883. p. 69 ff.

3) A. F. Stanley $K \in n t$, Researches on the struct. and function of the mammalian heart. Journ. of physiol. XIV. 1892. p. 233.

4) Vorläufig mitgetheilt durch $K r \cdot e h l$ und Romberg im Arch. f. exp. Pathol. u. Pharmak. XXX. Bd. 1892. p. 71. 
verbindenden Muskelfasern treten auf beiden Seiten augenscheinlich in directen innigen Contact mit den eigenen Muskelzellen der betreffenden Abtheilungen.

Nach Gaske11 ${ }^{1}$ ) zeigen die verbindenden Fasern morphologische Eigenthümlichkeiten, welche sie den embryonalen Herzmuskelfasern nähern. Sie scheinen auch in physiologischer Beziehung mehr embryonalen Charakter bewahrt zu haben. Von ihnen gehen im Allgemeinen die automatischen Contractionen aus, welche das Herz oder die von ihm abgetrennten Sticke zeigen. Das Vermögen automatischer Erregbarkeit bat sich in ibnen in höherem Masse erhalten, als in der übrigen Muskelsubstanz des Herzens. Wie zu erwarten, sind besonders die am Uebergang in die grossen Gefässe gelegenen Partien (Sinus venosus, Bulbus arteriosus) Stellen höherer automatischer Erregbarkeit.

Die Langsamkeit der Uebertragung des Reizes von Sinus auf Atrinm, von Atrium auf Ventrikel n. s. w., der sogenannte Block, bietet Ga ske 11 keine Schwierigkeiten. Wenn er die Vorkammer der Schildkröte durch einen Schnitt in zwei durch eine Muskelbrücke zusammenhängende Theile spaltete, so zeigte sich auch hier ein Block: zwischen der Contraction des direct gereizten und der des zweiten Stiicks lag eine Pause äbnlich dem normalen Intervall zwischen Vorkammer- und Kammersystole ${ }^{2}$ ).

Zur Stiitze von Gaskell's Annahme kann man sich jetzt auch auf die Beobachtungen von $\mathrm{G}$. $\mathrm{Fan} 0^{3}$ ) berufen, der beim embryonalen Hühnerherzen am dritten Tag der Bebrïtung bei $39^{\circ} \mathrm{C}$. die Fortpflanzungsgesehwindigkeit der Contractionswelle nur zwischen 11,5 und $3,6 \mathrm{~mm}$ gross fand, also ausserordentlich viel geringer als selbst die der Herzmuskelsubstanz des Frosches unter ziemlich normalen Verhältnissen bei viel niedrigerer Temperatur $\left(15-20^{\circ} \mathrm{C}\right.$.). Schreibt man, was ich für zulässig halte, den Blockfasern an der Atrio-Ventriculargrenze des Frosches eine normale Leitungsge-

1) W. H. Gaske11, On the innervation of the heart etc. Journ. of physiol. IV. 1883. p. 69 u. $70,72 \mathrm{ff}$.

2) W. H. Gaskell, ibid. p. 71. - Genau dieselbe Beobachtung hat am Ventrikel schon A. W. Volkmann gemacht. R. Wagner's Handwörterb. d. Phys. II. p. 616. 1844.

3) G. Fano, Sulla fisiologia del cuore embrionale del pollo. Arch. per le scienze med. Vol. XIV. 1890. 
schwindigkeit von etwa $5 \mathrm{~mm}$ in der Secunde, und eine Länge von etwa $1 \mathrm{~mm} \mathrm{zu}$, so ist die Dauer des Intervalls zwischen Vorkammer- und Ventrikelsystole genügend erklärt. Diese Dauer liegt nach meinen früheren Bestimmungen in der Norm zwischen 0,15 und $0,30^{\prime \prime}$.

Auch auf die antiperistaltische Bewegung weist $\mathrm{G}$ askell als Stütze für die Annahme rein muskulärer Leitung von Herzabschnitt zu Herzabschnitt. Er konnte das Herz des Rochens leicht in der Art schlagen lassen, dass - wie bei einer Ascidie - die Contractionen sich abwechselnd in der einen und in der entgegengesetzten Richtung fortpflanzten. Eine Umkehrung der Sehlagfolge der einzelnen Herzabtheilungen ist schon früher öfter bemerkt worden ( $\mathrm{Lud}$ wig, B id der, E ckhard, S e hiff u. a.) und gehört in der That zu den am leichtesten demonstrirbaren Thatsachen der Herzphysiologie ${ }^{1}$ ). Beruht der Rhythmus auf Muskelleitung, so versteht sich die Möglichkeit dieser Umkehrung von selbst. Die Nervenganglienhypothese kann nicht ohne vorläufig unbewiesene und unwahrscheinliche Hilfsannahmen auskommen. Durch die Contraction müssten sensible Nerven gereizt werden, welche die Muskelfasern des nächstvorhergehenden Herzabschnitts reflectorisch, also durch Vermittelung von Ganglienzellen in Erregung zn bringen hätten. Hierbei scheint die Annahme eines doppelsinnigen Leitungsvermögens im Reflexapparat - ein bisher nirgends sicher nachgewiesener Fall - unvermeidlich, wie denn ja schon das Vorkommen peripherischer Reflexe überhaupt von den“"zuverlässigsten Beobachtern gelängnet wird.

Gaskell suchte endlich noch auf einem andern Wege, dureb Aufhebung der nervösen Verbindungen zwischen Vorkammern und Kammern den Beweis zu liefern, dass Nerven und Ganglien bei der Reizübertragung im Herzen keine Rolle spielen. Er durchschnitt ${ }^{2}$ ) bei der Schildkröte die nach der Kammer ziehenden groben Nervenstämme und exstirpirte beim Frosch von der Kammer aus die Atrioventricularganglien und das untere Stück des Septum atriorum mit den darin befindlichen Nervenstämmen,

1) Die Abbildung eines dem Gaskell'schen entsprechenden Versuchs am Froschherzen gab ich in m. Aufsatz "das rhythmische Polyrheotom." Dies Arehiv. Bd. 52. 1892. p. 620. Fig. 8.

2) W. H. Gaske11, Joura. of Physiol. IV. p. 62 , ff. p. $75 \mathrm{ff}$. 
ohne dass damit die Leitung von Vorkammer nach Kammer aufgehoben worden wäre.

Aehnliche Durchschneidungsversuche sind neuerdings beim Kaninchen mit gleichem Erfolge von $\mathrm{Krehl}$ und $\mathrm{Romberg}{ }^{1)}$ ausgefïhrt worden. Auch sie berufen sich, ohne wie es scheint die Arbeiten früherer Autoren zu kennen, auf das Bestehen von Muskelbricken zwischen Vorhof und Kammer und führen ausserdem gegen die motorischen Functionen der Herzganglien ins Feld, dass diese Ganglien sich nach $\mathrm{H}$ is and $\mathrm{R}$ om $\mathrm{b}$ e rg ${ }^{2}$ ) aus den Ganglien des Grenzstrangs entwickeln, die ihrerseits aus derselben Anlage wie die Spinalganglien entstehen. Da letztere sensiblen Nerven zugehörten, muissten auch wohl die Herzganglien sensibler Natur sein. Ueberdies wïchsen die Herzganglienzellen erst spät ins Herz hinein, lange nachdem schon der normale Rhythmus sich entwickelt habe.

Ich glaube nicht, dass angesichts aller dieser neuen Thatsachen die alte Lehre von der Reiziubertragung im Herzen durch Vermittelung von Nervenfasern und -zellen noch für wahrscheinlich gelten darf. Dennoch scheint eine weitere Prüfung sehr rathsam. Die Anhänger der alten Lehre können sich immer noch darauf berufen, dass mit den Muskelbrücken auch Nerven übergehen, dass in den Versuchen mit Durchschneidung der verbindenden Nervenstämme vielleicht andere, feinere und darum bisher nicht bemerkte Nervencommissuren bestehen blieben, welche die Leitung vermittelten; dass von den Verhältnissen des embryonalen Herzens nicht auf die im entwickelten geschlossen werden dïrfe, in: dem sehr wohl eine weitere Arbeitstheilung stattgefunden haben könne u. s. w. Mich selbst machten einige gelegentliche Beobachtungen stutzig, die direct gegen Muskelleitung zu sprechen schienen und jedenfalls zur grössten Vorsicht mahnten.

Bei Reizung der Vorkammer eines nicht mehr spontan klopfenden Froschherzens in der Nähe des Sinus sah ich Kammercontractionen nach der gesetzmässigen langen Zeit - im vorlie-

1) L. Krehl und E. Romberg, Ueber die Bedeutung des Herzmuskels und der Herzganglien für die Herzthätigkeit des Säugethiers. Arch. f. experim. Pathol. u. Therapie. XXX. 1892. p. 49.

2) $\mathrm{H}$ is und Romberg, Verhandl. d. IX. Congr. für. innere Medicin. 1890. 
genden Falle etwa 0,8" - sich contrahiren ohne dass auch nur die Spur einer Contraction der Vorkammer zuvor bemerklich gewesen wäre. Die Bedingungen für die Beobachtung von Vorkammerbewegungen waren sehr günstig. Das ausgeschnittene Herz schrieb mittels eines sehr leichten, $12 \mathrm{mal}$ vergrössernden Aluminiumbebels, bei noch nicht $1 \mathrm{gr}$ Belastung seine Bewegungen nach der einfachen Suspensionsmethode auf. Die Reizung, durch einen sehr schwachen Schliessungsinductionsschlag mittels d'A r s o nv a l'scher Electroden, geschah in regelmässigen Intervallen von 3 Secunden durch das Polyrheotom, das zugleich die Oeffnungsströme abblendete. Das Ausbleiben der Vorkammercontractionen überraschte um so mehr, als diese bis dahin sehr deutlich gewesen waren und auch nachher wieder in gleicher Höhe wie zuvor $(3,5 \mathrm{~mm})$ auftraten. Die Latenzdauer hatte bei den 5 letztvorausgegangenen Reizungen betragen: $0,77^{\prime \prime}, 0,78^{\prime \prime}, 0,80^{\prime \prime}, 0,81^{\prime \prime}, 0,80^{\prime \prime}$. Sie mass in 5 diesen unmittelbar folgenden Fällen, bei denen die Vorkammer in Ruhe verharrte, $0,81^{\prime \prime}, 0,80^{\prime \prime}, 0,84^{\prime \prime}, 0,82^{\prime \prime}, 0,83^{\prime \prime}$, bei den 5 nächsten, mit wiederum sehr dentlichen $A_{s}: 0,80^{\prime \prime}, 0,81^{\prime \prime}$, $0,80^{\prime \prime}, 0,82^{\prime \prime}, 0,82^{\prime \prime}$. Die Höbe der Ventrikelcontractionen sank während dieser fünfzehn Reizungen nur von 22 auf $21 \mathrm{~mm}$. Hiermit schien in jedem Falle die Möglichkeit e iner motorischen Erregungsleitung von Vorkammernach Kammer durch nichtcontractile Bahnen erwiesen. Als solche Bahnen waren zunächst nur Nervenfasern und - wegen der langen Latenzzeit - Ganglienzellen zu vermuthen.

Eine weitere Reihe von Beobachtungen betraf Unterschiede im peristaltischen und antiperistaltischen Lẹitungsvermögen zwischen Vorkammern und Kammern. Es kam vor, dass beim selben Herzen zu gewisser Zeit nur in der einen oder nur in der andern Richtung eine Erregungsmittheilung möglich oder doch die Geschwindigkeit der Leitung in der einen Richtung sehr viel grösser als in der anderen war. Und zwar war die bevorzugte damn einmal die normale, dann wieder die entgegengesetzte. Ich babe früher ${ }^{1}$ ) schon einen solchen Fall flüchtig beschrieben und abgebildet. Dort erfolgte die antiperistaltische Reizibertragung geschwinder. Das auf Taf. IX Fig. 1 dargestellte Beispiel - ein einziges Paar aus einer längeren Reihe gleicher Versuche - zeigt

1) Dies Archiv B. 52 1892. S. 620. Fig. 8. 
das Gegentheil. In Fig. 1a wurde der Ventrikel rom linken Atrium aus, in Fig. $1 \mathrm{~b}$ die Atrien vom Ventrikel, dieser vom Bulbus arteriosus aus erregt. Zwischen beiden Versuchen lag ein Zeitraum von etwa 10 Sekunden. Das Intervall $A_{s} V_{s}$ in Fig. 1 a misst $0,6^{\prime \prime}$, das Intervall $A_{s} V_{s}$ in Fig. 1b 3,33", beiläufig einer der höchsten iberhaupt von mir beobachteten Werthe. Der Unterschied beträgt also tiber $2 \frac{1}{2}$ Secunden! So grosse Differenzen schienen bei der Annahme einfacher Muskelleitung schwer erklärlich. Fast noch überraschender erschien der in Fig. 2 a und b abgebildete Versuch (vom 10.11.91), wo in regelmässigen Intervallen Paare von je einer peristaltischen und einer antiperistaltischen Bewegung einander folgten. Die peristaltische begann und schien nun gleichsam von der Kammer aus reflectirt zu werden, wobei jedoch der ersten $V_{s}$ zunächst noch eine zweite $V_{s}$ und dann erst die zweite $A_{s}$ folgte. Dies Spiel wiederholte sich minutenlang in regelmässigen Intervallen: zwischen Bcginn der letaten Vorkammer contraction einer Gruppe und der ersten der nächstfolgenden Gruppe lag jedesmal eine Pause von etwa 6 Secunden.

Der sicherste Weg zur Entscheidung der Frage nach der Natur der Bahnen, welche den motorischen Impuls innerhalb der Vorkammern nach der Kammer hinleiten, schien mir in der directen Messung der Geschwindigkeit dieser Leitung gelegen. Das Princip der Versuche konnte dasselbe sein wie in den Versuchen von Helmholtz am Nervmuskelpräparat: die Vorkammer hatte nur an Stelle des Nerven, die Kammer an die des Muskels zu treten. Die Vorkammern mussten in verschiedener Entfernung von der Kammer gereizt und jedesmal das Latenzstadium fur die Ventrikelsystole gemessen werden. Die Dảuer der Latenz musste mit Entfernung der Reizstelle vom Ventrikel, speciell von der Mitte der Ventrikelbasis, sehr merklich wachsen, falls die Leitung im Atrium durch Muskelfasern besorgt wurde. Da die Fortpflanzungsgeschwindigkeit der Erregung in den Muskelfasern des Froschberzens hunderte mal kleiner ist als die in den motorischen Nerven, und beim Absterben erfahrungsgemäss rasch auf noch viel kleinere Werthe sinkt, durften Unterscbiede erwartet werden, die nach Zehntelsekunden rechneten. War die Leitang aber durch Nervenfasern vermittelt, so konnten bei den geringen Dimensionen der Vorkammern gröbere Unterschiede ỉberhaupt nicht erwartet werden, oder es konnte doch keine einfache Beziehung zwischen der Daner des 
Latenzstadiums und der Entfernung der Reizstelle vom Ventrikel bestehen. Denn alle Berechtigung fehlt um anzunehmen, dass ein Vorkammerreiz sich durch um so mehr, bezïglich durch um so weniger Ganglienzellen hindurch nach dem Ventrikel fortzupflanzen habe, je weiter von diesen entfernt er die Vorkammer traf.

\section{Zeitmessende Versuche über die Erregungsleitung im Herzen ${ }^{1}$ ).}

\section{A. Voruntersuchung.}

So einfach das Prinzip der Versuche war, so verwickelt und unbeständig erwiesen sich anfangs die Resultate. Es stellte sich alsbald heraus, dass die Dauer des Latenzstadiums von $V_{s}$ bei künstlicher Reizung der Vorkammer $\left(\rho A V_{s}\right)$ ausser vom Ort der Erregung in höchst auffälliger, den Sinn der Resultate unter Umständen geradezu verkehrender Weise von einer Reihe sehr verschiedenartiger Bedingungen abhängt, die sich bei allen Versuchen einmischen und deren Einfluss deshalb durch besondere Versuche zuvor festgestellt werden musste. Dieselben Einflüsse machen sich auch bei den spontanen Pulsationen in gleichem Sinne und gleichem Umfange geltend in Aenderungen des Intervalls $A_{s}-V_{s}$. Diese mögen deshalb mit jenen zusammen abgehandelt werden, was um so mehr erlaubt ist, als die Dauer von $\varrho A V_{s}$ immer nur wenig, und zwar um einen ziemlich constanten Betrag, vom Intervall $A_{s} \cdot V_{s}$ abweicht.

Es hat nämlich das Stadium $\varrho A_{s}$ der latenten Energie von $A$, bei directer Reizung von $A$, verglichen mit der Dauer des Intervalls $A_{s}-V_{s}$, im Ganzen nur einen geringen Werth (meist nur etwa $\left.0,1^{\prime \prime}\right)$, and erleidet auch unter Umständen, wo $A_{s}-V_{s}$ die grössten Schwankungen erfährt, nur geringfügige Aenderungen. Ich darf deshalb eine ausführliche Mittheilung der zahlreichen Versuche unterlassen, welche ich über die Abhängigkeit des Stadiums

1) Ich verwende im Folgenden wieder Kürze halber die früher vorgeschlagenen Symbole. Mit $g$ bezeiche ich ausserdem den Akt der Reizung, so dass $\varrho A$ die Reizung des Vorhofs bedentet, $\varrho A s$ die Latenzdauer der Vorhofsystole bei direkter Erregung von $A, \varrho A i V_{s}$ die Latenzdauer der Kammersystole bei Reizung der linken Vorkammer u. s. w. Vgl. Dies Archiv Bd. 52. 1892. p. 357 . 
der latenten Vorkammerreizung von verschiedenen Bedingungen angestellt habe, und bemerke hierïber nur Folgendes.

Der absolut niedrigste Werth der unter mehr als tausend der Messung zugänglichen Fällen jemals beim Froschherzen zur Beobachtung kam, war $0,045^{\prime \prime}$. Er wurde erhalten bei ultramaximaler Reizung einer frischen blutdurchströmten Vorkammer durch einen Schliessungsinduktionsschlag, bei $0,5 \mathrm{~g}$ Belastung und $20^{\circ} \mathrm{C}$. Unter gleichen Umständen konnte durch äusserste Abschwächung der Reizstärke nur eine Verlängerung der Latenzdaner auf 0,07 “ erzielt werden. Bei ausgeschnittenen, blutleeren; dem Absterben nahen, kaum mehr contractilen Vorkammern mass $o A_{s}$ bei stärkster Reizung noch immer nur $0,072^{\prime \prime}$, und im äussersten Falle, bei schwächster wirksamer Erregung durch einen Induktionsschlag und einer Belastung von 1 bis höchstens $1,5 \mathrm{~g}$ nicht mehr als $0.128^{4}$. Durch starke Abkühlung und starke Belastung können wohl noch höhere Werthe erreicht werden, aber diese Bedingungen waren in meinen zeitmessenden Versuchen nie realisirt, die alle bei gewöhnlicher Zimmertemperatur (meist zwischen $14^{\circ}$ und $18^{\circ} \mathrm{C}$.) und bei Belastungen zwischen 0,5 und $1,5 \mathrm{~g}$ angestellt wurden. Unter diesen Umständen kann aber das Intervall $A_{s}-V_{s}$ Schwankungen im Betrage von mehreren vollen Sekunden erfahren.

Es kommt sogar vor, dass $\varrho A$ abnimmt, während $A_{s} \cdot V_{s}$ gleichzeitig wächst. So wenn nach einer langen Ruhepause eine Reihe kurzer wirksamer Reizperioden folgen. Hier ist nach dem ersten Reize die Zeit $\varrho A_{s}$ ein Maximum, $A_{s}-V_{s}$ ein Minimum.

Gleich hier sei erwähnt, dass für das Stadium der latenten Reizung des Ventrikels bei direkter Erregung während Diastole oder Pause dasselbe gilt wie für $\varrho A_{s}$. Nur können bei $V$ etwas höhere absolute Werthe erreicht werden. Der geringste Werth für $\varrho V_{s}$ der beim Froseh je von mir gemessen wurde, betrug $0,045^{\prime \prime}$ (frisehes, blutdurchströmtes Herz, übermaximale Reizung durch einen Schliessungsinduktionsschlag), der höchste $0,28^{\prime \prime}$ (vor vielen Stunden ausgeschnittener, kaum mehr contractiler Ventrikel, bei schwächster noch eben genügender Reizung durch einen Schliessungsinduktionsschlag). Der gewöhnliche Werth liegt beim Frosch zwischen $0,08^{\prime \prime}$ and $0,15^{\prime \prime}$, was mit meinen eigenen früheren Messungen stimmt ${ }^{1}$ ). Für $R$. temporaria fand ich durchschnittlich etwas kürzere Latenzzeiten als für $R$. esculenta.

1) Dies Archiv, XI. 1875. S. 468. - M a r c h a n d, der die Verdicknng E. Pflüger, Archiv f. Pliýiologie, Bd. 56 
Die Umstände nun, welche sich in die Messungen der Leitungsgeschwindigkeit der Erregung von $A$ nach $V$ störend einmischen können, sind vor allem: Aenderungen des Blutstroms, der Reizpausen und Reizzahl und der Reizstärke. Von der Temperatur, die wie iuberall so auch hier die Schnelligkeit der physiologischen Leitung im böchsten Grade beeinflusst, sehe ich ab, da sie während der Dauer einer Versuchsreihe sich leicht genïgend constant erhaiten lässt. Ich will nur bemerken, dass das Intervall $A_{s}-V_{s}$ bei $5^{0} \mathrm{C}$. etwa 4-5 mal länger dauert als unter sonst gleichen Umständen bei $16-18^{\circ} \mathrm{O}$. Im selben Verhältniss ist, wie ich fand, auch die Leitungsgeschwindigkeit der $V$-Muskelfasern bei $5^{0} \mathrm{C}$. kleiner.

1) Einflus des Blutstroms auf die Dauer des Intervalls $A_{s}-V_{s}$.

Bei constanter Pulsfrequenz und normalem Blutstrom ist das Intervall $A_{s} V_{s}$ und ebenso das, nur um $0,05-0,15^{\prime \prime}$ längere Intervall $\varrho A V_{s}$, beim nämlichen Herzen sehr beständig. Man kann sich hiervon schon mittelst des einfachen Kammer-Suspensionsverfahrens ${ }^{2}$ ) am curarisirten oder durch Zerstörung von Gehirn und Rückenmark bewegungslos gemachten Froseh überzeugen. Da aber wie früher erwähnt, bei diesem Verfahren der Moment des Einsetzens von $V_{s}$ sich nicht ganz scharf bestimmen lässt, falls das Intervall $A_{s}-V_{s}$ nicht länger ist als die Dauer von $A_{s}$, und da namentlich auch der Anfang von $A_{s}$ sich nur dann schärfer markirt, wenn zwischen $V_{d}$ und $A_{s}$ eine merkliche Pause liegt, was beides beim frischen blutdurchströmten Herzen fast nie der Fall, so empfiehlt es sich, die Bewegungen von $A$ and $V$ einzeln, d. h. jede durch einen eigenen Schreibhebel, zu registriren. Auch hierzu eignet sich das Suspensionsverfahren vorzüglich. Man hat nur zu sorgen, dass bei der Suspension von $A$ nieht die Sinusgrenze und die Vagi gequetseht werden und die Bewegung von $A$ sich nicht dem Hebel von $V$ und die von $V$ sich nicht von dern Hebel von $A$ in störender Weise

registrirte, fand etwas höhere Werthe, was wohl an der Art des Registrirens lag. Dies Archiv XV. 1877. S. 511.

2) Beobachtungen und Versuche am suspendirtea Herzen. Dies Archiv Bd. 52. 1892. S. 327 . 
mittheilen. Ersteres vermeidet man am sichersten, wenn man die lin k e Vorkammer suspendirt und dabei den Haken oder Faden soweit wie möglich von $V$ und $S i$ einschlägt: Letzteres wird, wo nöthig, einfach dadurch vermieden, dass man einen mit Blat befeuchteten Faden dicken Zwirns quer iiber die $A-V$-Gr enze legt und seine Enden lose um die Vorderextremitäten des Froschs schlingt oder mit Stecknadeln auf einer Korkplatte fest steckt, auf welcher der Frosch liegt. Die Spannung des Fadens wird so gewählt, das die $A-V$-Grenze nur sanft niedergehalten aber durchaus nicht gequetscht wird. Das Blut muss unbehindert durchströmen können.

Zum registriren benutzte ich zwei dem früher beschriebenen ganz gleiche Schreibhebel von Aluminium. Ihre Axenlager sind am nämlichen Stativ wie die den Frosch tragende Korkplatte, zugleich aber auch jedes für sich vertikal und horizontal mittelst Schranbe verstellbar. Der mit $A$ verbundene Hebel zeichnete meist bei doppelter Vergrösserung und halb so grosser Belastung als der von $V$ bewegte, d. h. $A$ schrieb meist bei 12 maliger Vergrösserung und $0,5 \mathrm{gr}$ Belastung. Es ist leicht auf diese Weise $A_{s}$-Curven von $24-30 \mathrm{~mm}$ Gipfelhöhe zu verzeichnen.

Bei. andauernder Circulation bleiben die so erhaltenen Cardiogramme viele Stunden lang vollkommen identiseh.

Als Beispiel dienen Fig. $3 a$ und b, die von einem schwach curarisirten Exemplar von Rana esculenta stammen. Schon zwei Tage vorher waren $A_{s}$ und $V_{s}$ stundenlang registrirt worden. Die Häkchen waren seitdem im Herzen verblieben, das Thier unter einer Glasglocke feucht gehalten worden. Bei Beginn des neuen Versuchs fingen Reflexreizbarkeit und willkürliche Bewegurig eben an zurückzukehren. Die Zimmertemperatur war $18,5^{\circ} \mathrm{C}$. Fig. $3 \mathrm{~b}$ ist $1 \frac{3}{4}$ Stunden später als Fig. 3 a gezeichnet, während welcher Zeit $A$ und $V$ beständig registrirt hatten. Trotzdem haben sich weder Form noch Umfang, noch die zeitlichen Beziehungen von $A_{c}$ und $V_{c}$ merklich geändert; auch die Dauer der Herzperioden ist dieselbe geblieben.

Alsbald aber treten Aenderungen ein, wenn das Herz kein Blut mehr empfängt. Gleichviel ob die Pulsfrequenz sich ändert oder nicht: das Intervall $A_{s}-V_{s}$ fängt an zu wachsen, während die Grösse der Contraction, namentlich von $V$, abzunehmen pflegt. Je schneller das Herz blutleer wird, um so rascher erfolgen diese Aenderungen. Schliesslich fängt der Ventrikel an auszusetzen und folgt nur jeder zweiten $A_{s}$ eine $V_{s}$ mitunter auch steht $V$ bei 
fortklopfendem $A$ auf längere Zeit still. Ehe es soweit kommt, pflegt $A_{s}-V_{s}$ auf ein Vielfaches der normalen Dauer gewachsen zu sein, bisweilen auf das 10 bis 20 fache.

Als Beispiel sei die Fortsetzung des in Fig. 3 theilweise abgebildeten Versuchs mitgetheilt. Die Verblutung: war durch Abschneiden der grossen Hohlvenen hervorgebracht worden. Ausser der Dauer $(T)$ der Herzperiode und der Grösse des Intervalls $A_{s}-V_{s}$ sind auch die Dauer von $A_{s}$ und $V_{s}\left(t A_{s}\right.$ und $\left.t V_{s}\right)$ alle in Secunden and die Hubhöhen $h A$ and $h V$ in Millimeter verzeichnet. (7. Oct. 1893.)

Tabelle I.

\begin{tabular}{|c|c|c|c|c|c|c|c|}
\hline Zeit & $T$ & $A_{s}-V_{s}$ & $\hat{t} A_{s}$ & $t V_{s}$ & $h A$ & $h V$ & Bemerkungen \\
\hline $9 \mathrm{~h} \quad 0^{\prime}$ & 1,8 & 0,36 & 0,4 & 0,78 & 9,5 & 19,0 & Fig. 3a. \\
\hline $10 \mathrm{~h} 45^{\prime}$ & 1,8 & 0,36 & 0,4 & 0,78 & 9,5 & 19,0 & Fig. 3b. \\
\hline $50^{\prime}$ & $\hat{1,55}$ & 0,39 & 0,37 & 0,64 & 8,7 & 14,0 & $\begin{array}{l}10 \mathrm{~h} 48^{\prime} \text { Anfang des Ver- } \\
\text { blutens. }\end{array}$ \\
\hline $11 \mathrm{~h} 2^{\prime}$ & 1,50 & 0,39 & 0,37 & 0,58 & 5,5 & 15,5 & \\
\hline & 1,54 & 0,50 & 0,39 & 0,60 & 5,3 & 14,6 & Fig. 3c. \\
\hline $35^{\prime}$ & 3,05 & 0,74 & 0,42 & 0,62 & 5,2 & 8,5 & \\
\hline $40^{\prime}$ & 3,10 & 0,90 & 0,43 & 0,60 & 5,1 & 7,2 & \\
\hline & 3,10 & 1,05 & 0,43 & 0,58 & 5,0 & 6,5 & \\
\hline & 2,95 & 1,26 & 0,44 & 0,58 & 4,7 & 6,3 & \\
\hline $57^{\prime}$ & 2,90 & 1,28 & 0,44 & 0,58 & 4,5 & 6,4 & Fig. 3d. \\
\hline $59^{\prime}$ & 2,80 & 1,36 & 0,45 & 0,57 & 4,0 & 6,4 & \\
\hline $12 \mathrm{~h} 2^{\prime}$ & 2,46 & 1,63 & 0,45 & 0,57 & 4,2 & 6,6 & Fig. 3e. \\
\hline $4^{\prime}$ & 2,40 & 2,02 & 0,46 & 0,55 & 4,5 & 5,8 & \\
\hline - & 2,33 & 2,28 & 0,47 & 0,56 & 4,5 & 6,0 & $\begin{array}{l}\text { Fig. } 3 f . \\
\text { Nach } 12 \text { h } 5^{\prime} \text { fangen die } \\
\quad V_{s} \text { an auszusetzen. }\end{array}$ \\
\hline
\end{tabular}

Trotz der beträchtlich wachsenden Periodendauer ändert sich dureh das viel rasebere Zunehmen des Intervalls $A_{s}-V_{s}$ im vorstehenden Falle der Rhythmus der Herzbewegung, d. i. das Verhältniss $A_{s}-V_{s}: V_{s}-A_{s}$, nach dem Verbluten derart, dass es vom anfänglichen Werthe $1: 4$ innerhalb etwa einer Stunde auf $1: 2$, in weiteren 10 Minuten auf $1: 1$, daun sehnell unter $1: 0,2$ sinkt, bis endlich am Schluss des Versuchs die $V_{s}$ erst anhebt, wenn schon die folgende $A_{\varepsilon}$ beginnt. Hier entsteht also durch die Umkehrung des jambischen in den trochäischen Rhythmus allmählich der Eindruck eines antiperistaltischen Fortschreitens der Erregung von $V$ auf $A$ ("post hoc - propter hoc") und schliesslich gar der falsche Schein, als ob $V_{s}$ gleichzeitig mit $A_{s}$ erregt werde, die Leitungsverzögerung zwischen Vorkammer und Kammer Null sei. Es ist gut sich dieser Quelle von Täuschungen zu erinnern, wenn man die Entwickelung eines bestimmten Herzrbythmus 
nicht wie im vorliegenden Falle Schritt für Schritt hat verfolgen können.

Sehr anschauliche Resultate giebt auch das Studium dieser Veränderungen des Herzrhythmus mittels des einfachen Suspensionsverfahrens. Am durchsichtigsten sind die Aenderungen des Cardiogramms, wenn sich in Folge des Verblutens die Dauer der Perioden nicht oder doch nicht nennenswerth ändert, was häufig wenigstens längere Zeit hindurch nicht der Fall ist. Fig. 4 giebt hiervon ein Bild. Sie riihrt rom Herzen einer schwach curarisirten Rana temporaria her, der zwei Minuten vor dem Fig. $4 \mathrm{~b}$ entsprechenden Stadium die V. cava inferior durchgeschnitten wurde. Die Dauer der.Herzperioden, welche vorher um 1,35" schwankte, hielt sich weiterhin auf $1,40-1,45^{\prime \prime}$. Man sieht wie in Folge des Wachsens von $A_{s}-V_{s}$ sich zwischen dem Gipfel von $A_{s}$ und dem Beginn von $V_{s}$ ein Thal ausbildet, das tiefer und tiefer"und zugleich immer breiter wird. $A_{s}$ rückt in Folge dessen allmählich auf den von der vorhergehenden $V_{d}$ herrührenden Curvenabschnitt zurïck. In Fig. $4 \mathrm{e}$ ist der Werth von $A_{s}-V_{s}$ von $0,2-0,3^{\prime \prime}$ auf $0,7^{\prime \prime}$ gestiegen und die $A_{s}$ entsprechende Erhebung demzufolge beinahe auf dem Gipfel der vorhergehenden $\nabla_{s}$ angekommen. Ueberschreitet sie ihn, so treten weitere charakteristische Umgestaltungen des Cardiogramms ein, wovon noch in Fig. 5 ein Beispiel abgebildet sein möge.

Diese Figur ist vom Herzen einer curarisirten R. esculenta gezeichnet, der 5 Minuten vor dem in Fig. 5 a abgebildeten Stadium die untere Hohlvene geöffnet worden war. Zwischen den einzelnen Stadien liegen Zwischenräume von je etwa 5 Minuten, so dass das letzte (Fig. 5e) etwa eine halbe Stunde nach dem ersten (Fig. 5a) gezeichnet wurde. Hier nimmt zwar im Anfang des Versuchs $T$ so schnell ab, dass anch ohne Wachsen des Intervalls $A_{s}-V_{s}$ eine Superposition der $A_{s}$ anf die zunächst vorhergehende $V_{a}$ hätte erfolgen müssen. Von $5 \mathrm{c}$ an ist aber die Abnahme von $T$ so gering, dass sie keinen merklichen Einfluss mehr ausiubt.

Noch schneller pflegen sich - wegen des rascheren und vollständigeren Blutverlustes - die im Vorstehenden geschilderten Aenderungen nach dem Ausschneiden des Herzens zu entwickeln. Sie haben also im Herzen selbst ihren Ursprung, nicht in Aenderung äusserer Nerveneinfluisse. Dass es sich um einen directen Ein- 
fluss des Blutes handelt, zeigt sich auch darin, dass durch Bespülen des Herzens mit sauerstoffhaltigem Blat das verlängerte Intervall $A_{s}-V_{s}$ sich wieder verkürzen lässt, selbst wenn es schon auf die vielfache Dauer seines Anfangswerthes gewachsen war. Ja es kann auf diesem Wege das schon ganz geschwundene Leitungsvermögen zwischen $A$ und $V$ wiederhergestellt werden, was ja auch gewiss schon früher oft bemerkt worden ist.

Wie aus später mitzutheilenden Versuchen genügend hervorgehen wird, äussert sich der Einfluss des Verblutens in gleicher Weise, wenn das Herz durch künstliche, z. B. electrische Reize, vom Vorhof aus in regelmässiger Pulsation erhalten wird. Auch sei vorgreifend bemerkt, dass wie die normale so auch die Leitung in umgekehrter Richtung, von $V$ nach $A$, nach Aufhören des Blutstroms träger und träger erfolgt, und dasselbe gilt bezüglich der Leitung zwischen $S i$ und $A$ und zwischen $V$ und $B$.

Fìr unsere Aufgabe der Messung der Leitungsgeschwindigkeit des Erregungsprocesses für $V_{s}$ innerhalb $A$ ergiebt sich aus dem Vorstehenden die Vorschrift, in allen Fällen wo nicht in situ am blutdurchströmten Herzen gearbeitet wird, durch zeitlich streng symmetrische A nordnung: der Versuche unter regelmässigem Wechsel zwischen den näheren und den entfernteren Reizstellen die vom Aufhören des Blutstroms herrührenden Aenderungen der Latenzzeit unschädlich zu machen. Es ist das um so nöthiger, als die letzteren fast in keinem Falle sich mit gleichmässiger Geschwindigkeit entwickeln. Auch ist bei verschiedenen Herzen selbst unter anscheinend sehr ähnlichen Bedingungen der zeitliche Verlauf keineswegs immer identisch. Oft wächst $A_{s}-V_{s}$ anfangs sehr rasch, dann lange Zeit nur wenig; gelegentlich ist eher das Umgekehrte der Fall, selbst zeitweiliges Wiederabnehmen im Laufe eines längeren Versuchs gehört nicht zu den Unmöglichkeiten. Die Ursachen dieser individuellen Unterschiede können nachweislich sehr versehiedenen Ursprungs sein, wie Art des Thieres, Präparationsweise, restirender Blutgehalt des Herzens u. s. w. Es ist aber für den vorliegenden Zweck nicht nöthig, hierauf ausführlicher einzugehen.

2. Einflus der Reizpause auf die Daner des Intervalls $A_{s}-V_{s}$.

Das Bestehen dieses Einflusses folgt schon aus der bekann- 
ten Beobachtung, dass der Ventrikel wie durch directe künstliche Reize, so auch durch den natïrlichen, vom Vorhof kommenden Reiz überhaupt nur in gewissen Intervallen zur Contraction veranlasst werden kann. Der Ventrikel und - wie Lo é $^{1}{ }^{1}$ ) fand und ich bestätigen kann - anch die Vorkammern haben ihr refractäres Stadium, das im Allgemeinen mit der Systole zusammenfällt. Trifft also ein zweiter Reiz $A$ in diesem Stadium oder erreicht er von $A$ aus $V$ während dieser sich in Systole befindet, so wird $\varrho A V_{s}=\infty$. Im ersteren Falle folgt weder eine $A_{s}$ noch eine $V_{s}$, im zweiten bleibt $V_{s}$ aus. Aber auch wenn das refractäre Stadium für $V-$ und damit a fortiori, wegen dessen früheren Eintritts und kürzerer Dauer, auch das für $A$ - bereits vorbei, ja schon die anfängliche Reizbarkeit von $V$ völlig wiedergekehrt scheint, bleibt die Reiziibertragung von $A$ nach $V$ noch eine Zeit lang sehr merklich verlangsamt und erschwert. Hierin ist also ein nenes, sebr wirksames Mittel, neben dem in der eigenen Rhythmicität der Muskelsubstanz gelegenen gegeben, um den Ventrikel davor zu schiitzen, dass er sich zu bald wieder contrabire und dadurch die Blutzufuhr zum Arteriensystem gefährde.

Sogar dann, wenn die Dauer der Reizpause den Werth ïbersteigt, bei dem jede $A_{s}$ von einer $V_{s}$ gefolgt wird, ist anfangs dieser lähmende Einfluss noch deutlich, und es bedarf auch unter den normalen Umständen beim Froschherzen wohl immer wenigstens einiger Secunden Ruhezeit ehe er ganz geschwunder. Späterhin, beim Absterben, ist er oft nach Viertelminuten und später noch bemerklich. Innerhalb der angedenteten zeitlichen Grenzen reagirt $A_{s}-V_{s}$ im Allgemeinen sehr scharf auf Aenderungen der Reizpause, wohl ebenso scharf als nach $\mathrm{Bow} d \mathrm{it} \mathrm{e}^{\mathrm{t} h} \mathrm{~h}$ die Höhe der Contraction. Unterschiede in $T$ von nur wenig Procenten können sich deutlich verrathen.

Die Untersuchung dieser wìhtigen Abhängigkeit lässt sich leicht fruchtbar gestalten, da man die Varïrung der Pause innerhalb der weitesten Grenzen durchaus. in seiner Macht hat. Man kann sich von einer Reihe der wichtigsten Thatsachen aber anch schon ohne künstliche Reizung, am s p o n t a n klopfenden Herzen

1) Chr. Lovén, Ueber die Einwirkung von einzelnen Inductionsschlägen auf den Vorhof des Froschherzens. Mittheil, d. physiol. Labor. u.s.w. Stockholm. Heft 4 1886. p. 1. 
überzeugen, wenigstens wenn, wie häufig nach dem Ausschneiden, die Reizperioden grössere freiwillige Schwankungen, typische Gruppenbildung z. B. zeigen.

Ein Beispiel aus vielen dieser Art liefert der folgende

Versuch rom 5. Dec. 1893.

Herz einer R. esculenta. Um $2 \mathrm{~h} 5^{\prime}$ an der Si-grenze abgeschnitten. $V$ basis mit 2 Nadeln auf einem Korkprisma befestigt, das von einer am Hebelstativ verstellbaren Klemme festgehalten wurde. Klemme mit Herz in feuchter Kammer, einem oben offnen, unten durch einen Kork verschlossenen cylindrischen Gefäss, durch dessen abhebbaren Deckel die Fäden zu den Schreibhebeln führen ${ }^{1}$ ). Der eine Schreibhebel mit der Kammerspitze, der andere mit der linken Vorderecke des linken Atriums verbunden. Zeit in Stimmgabelschwingungen von $1 / 25^{\prime \prime}$ registrirt. Temperatur $13^{\circ} \mathrm{C}$.

Die spontanen Pulsationen, welche regelmässig von $A$ ausgingen, folgten sich in der ersten Zeit in kürzeren Gruppen von meist $3-6$ Schlägen. Die Dauer der Periodẹn nahm innerhalb einer Gruppe allmählich etwas ab; Dauer der Pausen zwischen den Gruppen meist 6-7 Sec., später viel weniger, wo dann auch die Zahl der zu einer Gruppe gehörigen Zuckungen grösser ward.

In den folgenden Tabellen bedeutet $T$ in Secunden die Zeit zwischen Anfang der beobachteten und der nächst vorhergehenden $A_{s .}$ Alle ïbrigen Bezeichnungen wie in der Tabelle I pag. 168.

Tabelle II a.

\begin{tabular}{r|c|c|c|c|c}
\hline Nr. & Zeit & $T$ & $A_{s}-V_{s}$ & $h A_{s}$ & $h V_{s}$ \\
\hline 1 & $2 \mathrm{~h} 7^{\prime}$ & 6,2 & 0,24 & 13,5 & 28,5 \\
2 & - & 2,8 & 0,32 & 12,5 & 27,1 \\
3 & - & 2,2 & 0,40 & 11,5 & 26,0 \\
& & & & & \\
4 & - & 6,3 & 0,26 & 13,5 & 28,5 \\
5 & - & 2,8 & 0,34 & 12,5 & 26,7 \\
6 & - & 2,2 & 0,40 & 11,5 & 25,2 \\
& & & & & \\
7 & - & 6,6 & 0,28 & 13,5 & 28,4 \\
9 & - & 2,9 & 0,36 & 12,7 & 26,7 \\
10 & - & 2,3 & 0,44 & 11,8 & 24,9 \\
& 2,2 & 0,49 & 11,5 & 24,3 \\
11 & $2 \mathrm{~h} 8^{\prime}$ & 6,8 & 0,28 & 13,5 & 28,3 \\
12 & - & 3,1 & 0,37 & 12,4 & 26,8 \\
& & & & &
\end{tabular}

1) Stativ und Klemmenvorrichtung entsprechen der in meiner Schrift „Ueber den Ursprung der Muskelkraft" 2. Auflage. Leipzig 1893, S. 22. Fig. 1 gegebenen schematischen Abbildung und Beschreibung. 
Es verflossen nun 5 Minuten während deren die Vorkammer wiederholt in Pausen von 4", später $2^{\prime \prime}$ durch einen Inductionșschlag erregt wurde. Danach kehren die spontanen Pulsationen in längeren Gruppen zurück. Die As waren während der künstlichen Reizung viel kleiner geworden, erholen sich aber bald ziemlich. $A_{s}-V_{s}$ zeigt schon eine bedeutende dauernde Zunahme gegen den Anfang, $h V_{s}$ eine mässige Abnahme.

Tabelle IIb.

\begin{tabular}{r|c|c|c|r|r}
\hline Nr. & Zeit & $T$ & $A_{s}-V_{s}$ & $h A_{s}$ & $h V_{s}$ \\
\hline 1 & $2 \mathrm{~h} 12$ & 3,8 & 0,54 & 7,2 & 24,5 \\
2 & - & 2,1 & 0,64 & 7,0 & 22,5 \\
3 & - & 1,1 & 0,70 & 6,9 & 21,8 \\
4 & - & 2,0 & 0,72 & 6,8 & 21,2 \\
& & & & & \\
5 & - & 3,6 & 0,54 & 10,5 & 24,8 \\
6 & - & 2,3 & 0,78 & 8,9 & 22,4 \\
7 & - & 2,0 & 0,86 & 7,9 & 22,0 \\
8 & - & 2,0 & 0,88 & 7,3 & 21,2 \\
9 & - & 2,0 & 0,88 & 6,9 & 21,3 \\
10 & - & 2,0 & 0,88 & 6,5 & 21,2 \\
& & & & & \\
11 & - & 3,6 & 0,53 & 10,5 & $\mathbf{2 4 , 5}$ \\
12 & - & 2,3 & 0,84 & 8,5 & $\mathbf{2 2 , 1}$ \\
13 & - & 2,1 & 0,90 & 7,5 & $\mathbf{2 1 , 7}$ \\
14 & - & $\mathbf{2 , 0}$ & 0,91 & $\mathbf{7 , 0}$ & $\mathbf{2 0 , 7}$
\end{tabular}

Das Herz wird jetzt zu einem 2stündigen Versuch über Einfluss anisotonischer Kochsalzlösungen benutzt, schliesslich längere Zeit von einem Gemeng von Rinderblutplasma and Froschblut bespült. Die spontanen Contractionen bilden danach sehr regelmässige, durch nur kurze Intervalle getrennte Gruppen von meist 5 oder 6 Perioden, innerhalb derer $T$ langsam abnimmt. Die an vier solcher Gruppen angestellten Zeitmessungen sind in Tab. II c vereinigt. Deber dieForm- und Grössenverhältnisse der Contractionen giebt ausserdem Fig. 6 Taf. IX Aufschluss, in welcher eine den 4 Gruppen von Tab. IIc folgende Gruppe in Orginalgrösse abgebildet ist.

Tabe 11 e II c.

\begin{tabular}{c|c|c|c}
\hline Nr. & Zeit & $T$ & $A_{s}-V_{s}$ \\
\hline 1 & $4 \mathrm{~h} 30^{\circ}$ & 2,6 & 1,46 \\
2 & - & 2,0 & 1,68 \\
3 & - & 1,8 & 1,79 \\
4 & - & 1,7 & 1,90 \\
5 & - & 1,7 & 1,96 \\
6 & - & 1,7 & 2,12
\end{tabular}




\begin{tabular}{r|c|c|c}
\hline Nr. & Zeit & $T$ & $A_{s}-V_{s}$ \\
\hline 7 & $4 h 30^{\prime}$ & 2,9 & 1,54 \\
8 & - & 2,0 & 1,68 \\
9 & - & 1,8 & 1,80 \\
10 & - & 1,75 & 2,00 \\
11 & - & 1,65 & 2,17 \\
12 & - & 2,8 & 1,43 \\
13 & - & 2,0 & 1,61 \\
14 & - & 1,8 & 1,79 \\
15 & - & 1,8 & 2,07 \\
16 & - & 1,8 & 2,13 \\
17 & - & 2,9 & 1,64 \\
18 & - & 2,0 & 1,94 \\
19 & - & 1,8 & 2,06 \\
20 & - & 1,7 & 2,18 \\
21 & - & 1,6 & 2,60
\end{tabular}

Für eine eindringendere Untersuchung des Einflusses der Reizpause auf die Dauer des Latenzstadiums $\varrho A V_{s}$ bedarf es selbstverständlich künstlicher Reizversuche mit methodischer Variirung der Reizpausen. Hier suchen sich aber die spontanen periodischen Reize störend einzumisehen. Will man nicht nene Complicationen einführen, so beseitigt man diesen Uebelstand besser nicht dadurch, dass man die spontanen Reize durch Stannius'. sehe Ligatur, Vagusreizung, Betupfen des Sinus mit Galle, u. dgl. unterdrückt, sondern einfach dadurch, dass man die Frequenz der künstlichen $A$-Reize etwas grösser wählt als die der natürlichen, welche sich gleichzeitig entwickeln. Es nimmt dann bei passender Stärke der künstlichen Einzelreize der Herzschlag bald die Periode der künstlichen Reize an. Man kann diese dann durch Steigerung der Reizfrequenz weiter verkürzen, bis zum Aussetzen von $V_{s}$, endlich zum Aussetzen auch von $A_{s}$. Aber auch den Einfluss längerer als der normalen Erregungspausen kann man auf diese Weise prüfen, da nach dem Aufhören einer längeren Reihe wirksamer künstlicher Reize die spontanen Bewegungen nicht sogleich wiederzukehren pflegen.

Einen merklichen Einfluss üben, wie die noch mitzutheilenden Versuche lehren, die spontanen Reize nicht, wenn sie nicht einen sichtbaren Erfolg auf $A$ haben. Dies gilt auch fiir ktinstliche $A$-Reize, wie noch weiter gezeigt werden soll, und kann selbst dann noch gelten, wenn dieselben eine zwar nicht in $A$ 
aber im Ventrikel sichtbar wirksam werdende Reizwelle auslösen!

Dagegen wird durch jede wirksame $A$-Reizung, a u ch wenn sie kein e $V_{s}$ a u s löste, das nächste Intervall $A_{s}-V_{s}$ vergrössert, wennschon nicht so stark als wenn dem ersten $A$-Reiz auch eine $V_{s}$ gefolgt wäre. Sowohl eine vorausgegangene Vorkammercontraction áls eiue vorhergegangene von $A$ ans veranlasste Kammercontraction wirken demnach verzögernd auf die Reizübertragung von $A$ nach $V$.

Näheres lehrt i. a. folgender

Ver s u ch vom 10. Nov. 1893. - Herz einer curarisirten R. esculenta, deren $A_{i}$ u. $V$ schon 2 Tage vorher zu Registrirversuchen gedient hatten, das aber bei wohlerhaltener Circulation noch in normaler Weise klopfte. $A i_{s}$ und $\mathrm{V}_{s}$ wurden in situ registrirt. Künstliche Reizung von $A i$ nahe beim Si mittels unpolarisirbarer Electroden (d'Arsonval'sche Silberdrähte mit Froschlungen überzogen) durch einzelne Oeffnungsschläge, die in regelmässigen Intervallen durch das rhythmische Polyrheotom erzeugt wurden. Die Abstufung der Reizfrequenz erfolgte durch Aenderung der Rotationsgesehwindigkeit des Rheotoms. Zwischen je zwei künstlichen Reizgruppen, die meist etwa 40 Reizungen umfassten, lag eine halbe Minute Pause, in der das Herz sofort wieder regelmässig spontane Pulsationeu ausführte, die in normaler Weise von Si ausgingen. Am Ende des Versuchs, der über 2 Stunden danerte, ist die Dauer der spontanen Perioden etwas kleiner als zu Anfang (1,7“ statt $\left.1,9^{\prime \prime}\right)$, das Intervall $A_{s}-V_{s}$ dementpréchend etwas grösser $\left(0,52^{\prime \prime}\right.$ statt $\left.0,42^{\prime \prime}\right)$, bei gleicher künstlicher Reïzperiode nicht länger als im Beginn des Versuchs (bei $T=1,4^{\prime \prime}$ nahezu $0,7^{\prime \prime}$ ); anch Dauer und Umfang der Systolen waren dieselben geblieben, ein Beweis dass durch die eingreifenden Manipulationen bleibende Schädigungen nicht hervorgerufen worden waren.

In den Tabellen bedeutet $T A$ das Intervall zwischen je zwei $A s, T V$ das Intervall zwischen je zwei $V_{s}$, bei künstlicher Reizung. Sinkt $T_{A} A$ unter einen gewissen Werth, so bleibt nach jeder zweiten $A_{s}$ eine $V_{s}$ aus, wird also $T V$ $=2 T A .-T_{1}$ ist das Reizintervall für $A_{s}$ bei spontaner Pulsation. Hier folgte jeder $A_{s}$ eine $V_{s}$. Aus jeder Reihe sind nur je fünf aufeinanderfolgende Perioden mitgetheilt, meist der Mitte der Reihe entstammend.

Tabelle III.

\begin{tabular}{|c|c|c|c|c|c|c|c|}
\hline Reihe & 1. & $T_{1}=1,85^{\mu}$ & $A s-V_{s}=$ & 0,42 & 0,42 & 0,42 & 0,43 \\
\hline ” & 2. & $T A=T V=1,35^{\prime \prime}$ & $n$ & 0,70 & 0,70 & 0,69 & 0,72 \\
\hline$n$ & 3. & $T^{\prime} A=\frac{T V}{2}=1,10^{\prime \prime}$ & $n$ & 0,65 & 0,65 & 0,65 & 0,64 \\
\hline 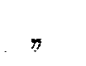 & 4 & $T A=\frac{T V}{2}=0,8^{u}$ & $"$ & 0,72 & 0,70 & 0,72 & 0,70 \\
\hline
\end{tabular}




$$
\begin{aligned}
& \text { Reihe 5. } T_{1}=1,75^{\prime \prime} \quad A s-V_{s}=0,54 \quad 0,53 \quad 0,52 \quad 0,53 \quad 0,52 \\
& \text { "6. } T A=\frac{T V}{2}=0,95^{\prime \prime} \quad \text { " } \quad 0,70 \quad 0,68 \quad 0,68 \quad 0,69 \quad 0,70 \\
& \text { "7. } T A=T V=1,8 " \quad \text { " } \quad 0,53 \quad 0,53 \quad 0,54 \quad 0,54 \quad 0,53
\end{aligned}
$$

Vergleichung von Reihe 1 mit 2 zeigt zunächst die starke Verlängerung des Intervalls $A_{s}-V_{s}$ beim Sinken der Periodendauer von 1,85 auf $1,35^{\prime \prime}$. - In Reihe 3 ist trotz Sinkens von $T A$ auf $1,10^{\prime \prime}$ die Leitung wieder beschleunigt. Der Grund liegt darin, dass nur auf jede zweite $A_{s}$ eine $V_{s}$ folgte, für $V$ also die Ruhepausen nicht 1,10" sondern etwa 2,2" betrugen. - Erst in Reihe 4, bei einer weiteren Verkürzung der Reizpanse auf $T A=$ $0,8^{\prime \prime}\left(T V=1,6^{\prime \prime}\right)$ ist das Intervall $\mathcal{A}_{s}-V_{s}$ soweit verlängert, wie es bei nicht alternirend aussetzender $V_{s}$ in Reibe 2 bei $T=1,35$ " gefunden ward.

Den schwächenden Einfluss bloss der $A_{s}$ zeigt auch Vergleichung von Reihe 5 und 7 mit 6 . Trotzdem in 6 das Reiz-Intervall $T V 1,9^{\prime \prime}$, also mehr beträgt, ist die Leitung beträchtlich verzögert. Jedoch offenbar nicht so viel, wie wenn auch fur $T V$ die Periode $0,95^{\prime \prime}$ bätte werden können.

Dasselbe zeigen noch die folgenden Reihen:

$$
\text { T a belle IV. }
$$

$$
\begin{aligned}
& \text { Reihe 8. } T A=T V=1,40^{\prime \prime} \quad A_{s}-V_{s}=0,74 \quad 0,76 \quad 0,75 \quad 0,73 \quad 0,74 \\
& \text { " 9. } T A=\frac{T V}{2}=0,90^{\prime \prime} \quad \text { " } \quad 0,72 \quad 0,73 \quad 0,73 \quad 0,72 \quad 0,72 \\
& \begin{array}{llllllll}
10 . & T_{1}=1,78^{\prime \prime} \quad, & 0,53 & 0,53 & 0,51 & 0,52 & 0,53
\end{array} \\
& \text { " 11. } T A=T V=1,40^{\prime \prime} \quad, \quad 0,72 \quad 0,73 \quad 0,73 \quad 0,73 \quad 0,74
\end{aligned}
$$

Die Schwächung ist lant Reihe 8, 9, 10 beim Reizintervall $0,9^{\prime \prime}$ gerade so gross, aber nicht grösser als beim Reizintervall 1,4", denn im letzteren Falle kam auch $V_{s}$ zu Stande und konnte durch seine schwächende Wirkung die von $A_{s}$ verstärken.

Zum Belege, dass un w i ks ame natürliche Reize keinen Einfluss baben, könnte dienen

$$
\begin{aligned}
& \text { Tabelle V. }
\end{aligned}
$$

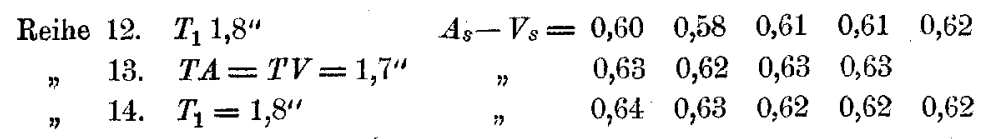

Da jedoch bier das Ausbleiben jedes merklichen Einflusses auch darauf beruht hahen kanu, dass infolge der wirksamen künst- 
lichen Erregung die Entwickelung der spontanen Reize überhaupt nicht zu Stande kam, seien einige Versuchsreihen mitgetheilt, in denen, während spontaner regelmässiger Pulsationen des Herzens entweder $A$ oder $V$ mit eben unwirksamen Inductionsströmen gereizt wurden. Die Versuche sind am nämlichen Herzen wie die von Tabellen III $-\mathrm{V}$ angestellt. Mit $T_{\varrho}$ ist das Tempo des künstlichen, mit $T_{1}$ das der antomatischen Reize bezeichnet.

$$
\text { T a b e lle VI. }
$$

Reizung der Ventrikelbasis mit eben unwirksamen Inductionsströmen.

$$
\begin{aligned}
& \text { Reihe 1. } T_{1}=1,7^{\prime \prime} \quad A_{s}-V_{s}=0,56 \quad 0,57 \quad 0,55 \quad 0,56 \quad 0,58 \\
& \text { "2. } T_{1}=1,7^{\prime \prime}, T \varrho=1,35^{\prime \prime} \quad " \quad 0,57 \quad 0,55 \quad 0,57 \quad 0,58 \quad 0,56
\end{aligned}
$$

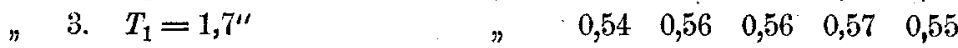

\section{Tabelle VII.}

Reizung der Vorkammer mit eben unwirksamen Inductionsschlägen.

$$
\begin{aligned}
& \text { Reihe 1. } T_{1}=1,8^{\prime \prime} \quad A_{s}-V_{s}=0,50 \cdot 0,51 \quad 0,52 \quad 0,52 \quad 0,50 \\
& \text { "2. } T_{1}=1,8^{\prime \prime}, T^{\prime}=1,50^{\prime \prime} \quad \text { " } \quad 0,50 \quad 0,50 \cdot 0,51 \quad 0,52 \quad 0,52
\end{aligned}
$$

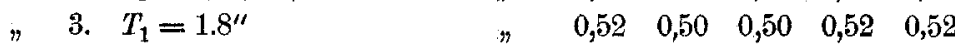

Eine an und für sich unwirksame Reizung von $A$ kann indirect dadurch Einfluss gewinnen, dass sie die Frequenz des spontanen Reizes vermehrt, die automatische Erregbarkeit steigert. Nur müssen aber, wie es scheint, die Herde der automatischen Erregung direct oder mittelst acceleratorischer Nerven vom Reiz getroffen werden. Im Versuch der folgenden Tabelle waren die Reize unwirksam, weil sie in das refractäre Stadium von $A$ fielen.

T a belle VIII.

\begin{tabular}{c|c|c|c|c|c}
\hline $\begin{array}{c}\text { Nr. der } \\
\text { Periode }\end{array}$ & $T$ & $A_{s-V_{s}}$ & $\begin{array}{l}\text { Nr. der } \\
\text { Periode }\end{array}$ & $T$ & $A_{s}-V_{s}$ \\
\hline 1 & 1,81 & 0,56 & 9 & 1,41 & 0,70 \\
2 & 1,80 & 0,57 & 10 & 1,37 & 0,69 \\
3 & 1,81 & 0,57 & 11 & 1,35 & 0,68 \\
4 & 1,79 & 0,58 & 12 & 1,38 & 0,67 \\
5 & 1,82 & 0,56 & 13 & 1,34 & 0,66 \\
6 & 1,81 & 0,56 & 14 & 1,40 & 0,63 \\
7 & 1,55 & 0,63 & 15 & 1,49 & 0,65 \\
8 & 1,42 & 0,68 & & &
\end{tabular}

Von Periode 6 an wurde $A i$ in regelmässigen Intervallen von 1,36 Sec. durch einen Oeffnnngsinductionsstrom gereizt. Schon die 7. Periode kommt erheblich friher, was sogleich zu einer Verzögerung 
der Leitung nach $V$ führt. Von hier an ist dann die Dauer der Perioden noch weiter verkiurzt und wächst dem entsprechend des Intervall $A_{s}-V_{s}$ weiter. 'Von Versuch 15 an folgte jeder Reizung eine Contraction von $A$ mit den nahezu constanten Latenzzeiten $\varrho A_{s}=0,15^{\prime \prime}$ und $\varrho A V_{s}=0,87^{\prime \prime}$.

In den im Vorstehenden mitgetheilten Versuchen war das Herz in situ und andauernd von Blut durchströmt. Am ausgeschnittenen, blutfreien oder doch sebr blutarmen Herzen wächst der absolute Betrag der leitungshemmenden Wirkung der Contraction und ebenso die Dauer der zur Wiederberstellung erforderlichen Zeit bedeutend. Eine völlige Wiederherstellung kommt übrigens wegen des an und für sich unter diesen Umständen stattfindenden beständigen Wachsens des Intervalls $A_{s}-V_{s}$ kaum zur Beobachtung.

Versuch vom 21. November 1893.

R. esculenta. Curarisirt. Herz um $10^{\mathrm{h}}$ ansgeschnitten, anf Kork befestigt, in féuchter Kammer. Künstliche Reizung von $A$, nahe am Si, mit einzelnen Inductionsschlägen in constanten, von Minute zu Minute symmetrisch wechselnden Intervallen $T$. - Beginn von Reihe 1 in Tab. IX um $12^{\mathrm{h}} 55^{\prime}$.

$$
\text { T a belle IX. }
$$

$\begin{array}{cccccccccc}\text { Reihe 1. } & T=4,5^{\prime \prime} & A_{s-}-V_{s}=0,88 & 0,93 & 0,108 & & & \\ " & 2 . & T=9,0^{\prime \prime} & " & 0,68 & 0,70 & 0,70 & 0,73 & 0,74 & 0,75 \\ " & 3 . & T=4,5^{\prime \prime} & " & 1,17 & 1,20 & 1,24 & 1,40 & & \end{array}$

3. Einfluss der Zahl der vorbergegangenen wi k kame n Reize auf die Dauer des Intervalls $A_{s}-V_{s}$.

Schon ans dem Versuch Tabelle IX und ans Tabelle IIc geht hervor, dass die lähmende Wirkung eines einzelnen Reizes auf die Leitung von $A$ nach $V$ so lange anhalten kann, dass leicht eine Summation der verzögernden Wirkungen aufeinander folgender Reizungen eintritt. Bei Reizungen in gleichen Intervallen sieht man deshalb, falls die Dauer der Reizperiode nicht länger als zur völligen Wiederherstellung des Leitungsvermögens nöthig, die Dauer des Intervalls $A_{s}-V_{s}$ mit der Zahl der Reize wachsen bis zu einem Maximum, auf dem sie dann sich erhält, oder - bei kürzerer Reizpause oder grösserer Ermüdbarkeit - so lange, bis schliesslich einmal gar keine Leitung mehr erfolgt, $V_{s}$ ausbleibt. Wegen der nunmehr für $V_{s}$ gegebenen längeren Ruhezeit erholt 
sich dann das Uebertragungsvermögen: auf die nächste $A$ folgt wieder nach kürzerer Latenz eine $V_{s}$, dieser wieder eine Reihe $V_{s}$ mit wachsender Latenzzeit, dann fällt wieder eine $V_{s}$ aus u. s. f.

Zur Constatirung dieser Thatsachen mittelst künstlicher Reizung: muss man hièrnach die Reizperiode kleiner wählen, als die der gleichzeitig etwa vorhandenen automatischen Erregungen, aber nicht so klein, dass auf jede $\mathrm{n}$ zweiten Reiz eine $V_{s}$ ausbleibt. Wenigstens nicht, wenn die Herzen noch ziemlich frisch sind, denn es hat sich dann zwischen je zwei $V_{s}$ leicht wieder $A_{s}-V_{s}$ auf einen constanten Werth eingestellt.

Zur Erläuterung einige Beispiele.

Versuch vom 6. November 1893 .

Herz von R. temporaria, in situ, blutdurchströmt. Doppelsuspension $\left(A_{i}\right.$ und $V$ ). Temperatur $18^{\circ}$ C. Spontane, in regelmässigen Intervallen $\left(T=2,0^{\prime \prime}\right)$ von $A$ ausgehende Pulsationen, abwechselnd mit künstlicher Reizung von $A$ in constanten Intervallen $T_{1}$, in etwa $4 \mathrm{~mm}$ Entfernung von der $A-V$-Grenze durch je einen Oeffnungsinductionsschlag mittels des rhythmischen Polyrheotoms. Ein Strich $(-)$ bedeutet, dass eine $V_{s}$ ausblieb.

Tabelle X.

\begin{tabular}{|c|c|c|c|c|c|c|c|c|}
\hline \multirow[t]{2}{*}{$2 \mathrm{~b} 40^{\prime}$} & 1. & $T=2,00$ & $A_{s}-V$ & $=0,52$ & 0,52 & 0,51 & 0,52 & \\
\hline & 2. & $T_{1}=1,09$ & r & 0,64 & 0,80 & 0,81 & 0,82 & \\
\hline $41^{\prime}$ & 3. & $T_{1}=1,09$ & 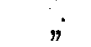 & 0,83 & 0,85 & 0,85 & 0,84 & \\
\hline $42^{\prime}$ & 4. & $T=2,00$ & $\eta$ & 0,52 & 0,54 & 0,53 & 0,53 & \\
\hline \multirow[t]{2}{*}{$2 \mathrm{~h} 50^{\prime}$} & 5. & $T=2,00$ & $\eta$ & 0,52 & 0,52 & 0,53 & 0,52 & \\
\hline & 6. & $T_{1}=1,05$ & $\pi$ & 0,63 & 0,74 & 0,75 & 0,77 & \\
\hline $51^{\prime}$ & 7. & $T_{1}=1,05$ & 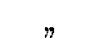 & 0,77 & 0,79 & 0,80 & 0,81 & 0,83 \\
\hline $52^{\prime}$ & 8. & $T=\mathbf{2}, 00$ & $"$ & 0,53 & 0,52 & 0,53 & 0,53 & \\
\hline \multirow[t]{2}{*}{$4 h 5^{\prime}$} & & $T=2,00$ & $"$ & 0,80 & 0,80 & 0,79 & 0,79 & \\
\hline & 10. & $T_{1}=1,20$ & ?. & 0,82 & 1,10 & 1,25 & $-0,98$ & $1,22-0,98 \quad 1,22$ \\
\hline $6^{\prime}$ & 11. & $T=2,00$ & " & 0,85 & 0,84 & 0,83 & 0,83 & \\
\hline
\end{tabular}

Versuch vom 10. November 1893.

Mittelgrosse R. temporaria. Seit 2 Tagen schwach curarisirt. Herz in situ, blutdurchströmt. Doppelsuspension ( $A i$ und $V$ ). Ai gereizt in sehr langsam abnehmenden, dann wieder etwas wachsenden Intervallen $T$. Die allmählichen denderungen des Reiztempo werden hervorgebracht mittels einer in den Kreis des $\mathrm{Helm} \mathrm{holtz}$ 'schen Motor, der das Rheotom treibt, eingeschalteten Widerstandsschraube. Die erste Contraction der Tabelle ist noch eine spontane. - Temperatur $14^{\circ} \mathrm{C}$. 
Tabelle XI.

\begin{tabular}{|c|c|c|c|c|c|}
\hline $\mathrm{Nr}$. & $T$ & $A_{s}-V_{s}$ & Nr. & $T$ & $A_{s}-V_{s}$ \\
\hline 1 & 1,34 & 0,62 & 9 & 1,29 & - \\
\hline 2 & 1,33 & 0,68 & 10 & 1,29 & 0,71 \\
\hline 3 & 1,33 & 0,79 & 11 & 1,29 & - \\
\hline 4 & 1,32 & 0,81 & 12 & 1,27 & 0,70 \\
\hline 5 & 1,32 & 0,81 & 13 & 1,26 . & - \\
\hline 6 & 1,31 & 0,81 & 14 & 1,29 & 0,65 \\
\hline 7 & 1,31 & 0,81 & 15 & 1,28 & - \\
\hline 8 & 1,30 & 0,01 & 16 & 1,28 & 0,65 \\
\hline
\end{tabular}

Einen ähnlichen Versuch mit etwas grösseren Schwankungen von $T$, fünf Minuten nach dem vorigen, am selben Herzen angestellt, giebt

T a b elle XII.

\begin{tabular}{|c|c|c|c|c|c|}
\hline $\mathrm{Nr}$. & $T$ & $A_{s}-V_{s}$ & Nr. & $T$ & $A_{s}-V_{s}$ \\
\hline 1 & 1,79 & 0,68 & 9 & 1,15 & 0,72 \\
\hline 2 & 1,69 & 0,66 & 10 & 1,10 & - \\
\hline 3 & 1,70 & 0,67 & 11 & 1,10 & 0,74 \\
\hline 4 & 1,70 & 0,67 & 12 & $\mathbf{1}, 20$ & - \\
\hline 5 & 1,65 & 0,64 & 13 & 1,40 & 0,68 \\
\hline 6 & 1,45 & 0,75 & 14 & 1,60 & 0,70 \\
\hline 7 & 1,34 & 0,80 & 15 & 1,90 & 0,63 \\
\hline 8 & 1,22 & - & 16 & 1,90 & 0,64 \\
\hline
\end{tabular}

Noch angenfälliger zeigt sich die ermüdende Wirkung des Erregungsvorgangs und deren Summation bei Anwendung des einfachen Suspensionsverfahrens. Die Aenderungen des Intervalls $A_{s}-V_{s}$ führen hier zu solchen Umgestaltungen des Cardiogramms, dass der Eindruck einer vollkommenen Unregelmässigkeit erzeugt wird, der freilich bei näherer Betrachtung nur einer um so schöneren Gesetzmässigkeit weicht.

Als Beiweis diene der in Fig.7 abgebildete Fall. Das ausgeschnittene Herz wurde hier von $A_{i}$ aus mit einzelnen Inductionsschlägen mittels des Polyrheotoms erregt. Die Reize folgten sich in regelmässigen Gruppeu von 6 im Rhythmus 8:5:4:3:4:8. Zu dem Ende waren in der Scheibe des Pol yrheotoms 6 Kupferfedern in den Winkelabständen von $8,5,4,3,4,8$, eingesetzt. (Die Scheibe besass 32 in gleichen Wurzelabständen stehende Löcher, nicht 36 wie die späteren Exemplare.) Eine Umdrehung der Scheibe erfolgte in 16 Secunden, entsprechend den absoluten Werthen der Reizintervalle: $4,2,5,2,1,5,2,4$ Secunden. 
Vier der in Fig. 7 abgebildeten ähnliehe Gruppen, welche vom selben Herzen bei grösserer Rotationsgeschwindigkeit der Schreibfläche anfgezeichnet und ausgemessen wurden, ergaben folgende Aenderungen der Werthe von $A_{s}-V_{s}$.

T abellè XIII.

\begin{tabular}{r|c|c|c|c|c}
\hline $\mathrm{Nr}$. & $T$ & $A_{8}-V_{s}$ & $\mathrm{Nr}$. & $T$ & $A_{s}-V_{s}$ \\
\hline 1 & 4,0 & 0,88 & 13 & 4,0 & 0,88 \\
2 & 2,5 & 0,90 & 14 & 2,5 & 0,94 \\
3 & 2,0 & 1,00 & $\mathbf{1 5}$ & 2,0 & $\mathbf{1}, 02$ \\
4 & 1,5 & 1,60 & $\mathbf{1 6}$ & $\mathbf{1 , 5}$ & $\mathbf{1 , 7 0}$ \\
5 & 2,0 & - & 17 & 2,0 & $-\overline{0}$ \\
6 & 4,0 & 0,90 & 18 & 4,0 & 0,90 \\
7 & 4,0 & 0,90 & 19 & 4,0 & 0,82 \\
8 & 2,5 & 0,95 & 20 & 2,5 & 0,82 \\
9 & 2,0 & 1,00 & 21 & 2,0 & 0,93 \\
10 & 1,5 & 1,63 & 22 & 1,5 & 1,60 \\
11 & 2,0 & - & 23 & 2,0 & - \\
12 & 4,0 & 0,88 & 24 & 4,0 & 0,88
\end{tabular}

Es bedarf keiner näheren Ausführung, welchen entscheidenden Einfluss nach den vorstehenden Versuchen Grösse und Zahl der vorausgegangenen Reizpausen auf die Messungen der Leitungsgeschwindigkeit des Bewegungsreizes fuil $V$ innerhalb $A$ werden ausüben können. Die Versuche werden stets so eingerichtet werden mïssen, dass Dauer und Zahl der vorausgegangenen Reizperioden von gleicher und zwar von solcher Grösse sind, dass $A_{s}-V_{s}$ einen constanten ëndlichen Werth angenommen hat.

4. E in $1 \mathrm{u} s \mathrm{~s}$ der Reizstär k e auf das Litervall $A_{s}-V_{s}$.

Den Einfluss der Reizstärke habe ich mittelst des Polyrheotoms für Schliessungs- und Oeffnungsinductionsströme und für Stromstösse untersucht.

Wenn man den Vorhof vom nämlichen Orte aus mit electrischen Reizen verschiedener Stärke erregt, so erhält man im allgemeinen verschiedene Werthe für die Latenz $A_{s}-V_{s}$. Die Differenzen können hunderte von Procenten, eventuell $2^{\prime \prime}$ and mehr betragen. Die Dauer $A_{s}-V_{s}$ nimmt stets mit wachsender Reizstärke ab. Dabei ist Folgendes zu bemerken:

Reizt man $A$ in der Nähe von $V$, so nimmt mit von Null aus wachsender Stromstärke $A_{s}-V_{s}$, im allgemeinen anfangs conE. Paùger, Archiv f. Phyriologie. Bd. 56 . 
tinuirlich, dann meist plötzlich, in einem Sprung, ab, um bei weiterer Steigerung der Stromstärke nur noch wenig kỉirzer zu werden. Der durch den Sprung erreichte geringere Werth (meist 0,1-0,2“) ist derselbe, der auch bei directer Reizung von $V$ erhalten wird. Er verdankt denn auch, wie directe Controlversuche mit dem stromprüfenden Froschschenkel lehren, einer directen Erregung von $V$ durch Stromschleifen seinen Ursprung. Rickt man mit den Electroden weiter von $V$ weg, so bedarf es immer grösserer Stromstärken, um jene sprungweise Abnahme von $A_{s}-V_{s}$ eintreten zu sehen. Desgleichen, je kürzer die intrapolare Strecke ist.

Aber auch wenn die Reizelectroden genügend weit von $V$ entfernt liegen und die Stromstärke innerhalb solcher Grenzen bleibt, dass directe Erregung von $V$ durch Stromzweige ausgeschlossen ist, nimmt $A_{s}-V_{s}$ mit wachsender Stromstärke ab und kommen selbst kleinere sprungweise Aenderungen vor. Die letzteren beruhen, wie die lange absolute Dauer von $A_{s}-V_{s}$ in solchen Fällen lehrt, sicher nicht anf Stromschleifen die $V$ trafen. Ihre Ursache liegt, wie später noch näher bewiesen werden wird, zum weitaus grössten Theil darin, dass mit wachsender Stromstärke immer näher an $V$ heran liegende Stellen von $A$ Ausgangspunkte der Erregung werden. Es sind ja bekanntlich nicht die Berührungsstellen der Reizelectroden mit der Herzoberfläche, sondern diejenigen Stellen die Orte der directen Erregung, an denen der Strom aus den reizbaren Muskelfasern in die Umgebung aus- oder eintritt. Bei einer netzformigen Muskelfasermasse, deren Bündel so dünn und dabei von so unregelmässigem Verlảuf sind, wie die des Atrium, werden in der Nähe der wirksamen äusseren Electrode im allgemeinen sebr viele dieser „inneren Electroden" liegen, und zwar um so mehr und in um so weiterem Umkreise von der äusseren, je stärker der erregende electrische Strom. Dabei sind die gelegentlich vorkommenden sprungweisen Aenderungen ron $\varrho A V_{s}$ mit der Stromstärke nicht befremdend.

5. E influs der Spannu $\mathrm{g}$ auf das Intervall $A_{s}-V_{s}$.

Da die Spannung; welcher Vorkammer und Kammer bei Anwendung des Supensionsverfahrens ansgesetzt sind, nicht immer dieselbe ist und auch wohl gelegentlich im nämlichen Versuche aus praktischen Grínden etwas varürt wird, war es nöthig, ibren etwaigen Einfluss auf $A_{s}-V_{s}$ durch eigene Versuche festzustellen. 
Es konnte ein indirecter Einfluss bestehen durch Aenderung der Reizpause, der sich wenigstens beim spontan klopfenden Herzen deutlich zeigen musste. Es war aber auch denkbar, dass unabhängig hiervon unter den Bedingungen des Suspensionsverfahrens directe Aenderungen jenes Intervalls anftraten.

Die Spannungen, denen $A$ und $V$ in meinen Versuchen ausgesetzt waren, wechselten beim ausgeschnittenen Herzen nur zwischen etwa 0,5 und $2 \mathrm{gr}$. Die gewöhnliche Spannung betrug $1,0-1,5 \mathrm{gr}$. Es geniugte darum völlig, den Einfluss von Spannungen zwiseben 0,1 und 12 gr zu untersuchen.

Hierbei ergab sich nun im allgemeinen weder ein indirecter, noch ein directer merklicher Einfluss. Da man gewöhnlich der Spannung der Herzmuskelfasern einen Einfluss auf die Pulsfrequenz zuschreibt, durfte wenigstens eine Aenderung im Tempo erwartet werden. Aber hiervon zeigte sich nichts. Jedenfalls nicht eine nnzweifelhafte Beschleunigung des Tempos bei steigender Belastung, gelegentlich wohl einmal eher das Gegentheil. Die Frequenzändernde Wirkung, welche von verschiedenen Beobachtern bei der Aenderung des intracardialen Blutdrucks gefunden wurde, kann also schwerlich ihren directen Grund in der veränderten Dehnung der Muskelwand haben, sondern muss auf anderem Wege erklärt werden. Vermuthlich spielt, wie ich schon bei Gelegenheit meiner Untersuchung des Bulbus arteriosus ${ }^{1}$ ) bemerkt habe, die veränderte Durchspülung mit Ernährungsflüssigkeit die Hauptrolle. Es liegt nicht im Plan der vorliegenden Untersuchung, diesen Punkt näher zu behandeln. Da meine Versuche aber durch ihre negativen Resultate mit der herrschenden Vorstellung in Streit sind, sei es gestattet, eine etwas grössere Zahl von experimentellen Belegen mitzutheilen.

Die Aenderung der Belastung erfolgte in den folgenden Versuchsbeispielen immer durch Verscbieben eines Laufgewichtes am Schreibhebel. Die Versuche wurden symmetrisch in Bezug auf die Zeit eingerichtet, d. h. die Belastung auf- und absteigend gewechșelt. In den Tabellen sind alle zur gleichen Belastung gehörigen Werthe in eine Reihe aufgenommen und nur die Mittelwerthe mitgetheilt.

a) Einfluss verschiedener Belastung auf das Tempo $(T)$ der spontanen Vorkammercontractionen.

1) Dies Archiv. Bd. 29, 1882. S, 468. 
Versuch vom 23. November 1891.

Vorkammer ausgeschnitten, am Sinus eingeklemmt, suspendirt in feuchter Kammer. Ventrikel abgeschnitten, Temperatur $17^{\circ} \mathrm{C}$.

\section{Tab e 11 e XIV.}

1. Belastung $0,1 \mathrm{gr} \quad T=1,815^{\prime \prime}$ (Mittel aus 70 Perioden)

2. " $0,5 \mathrm{gr} \quad, 1,818^{\prime \prime} \quad$ " 40 "

3. $" 1,0 \mathrm{gr} \quad, 1,836^{\prime \prime} \quad$ " " 70 "

4. . " $1,5 \mathrm{gr} \quad, 1,825^{\prime \prime} \quad$ " 20 "

5. " $2,0 \mathrm{gr}, 1,850^{\prime \prime} \quad$ " 30 "

6. " $3,0 \mathrm{gr} \quad$ " $1,816^{\prime \prime} \quad$ ", $25 \quad$,

Versueb vom 23. Jan u ar 1892.

Ebenso behandelte Vorkammer. Temperatur anfangs $15.5^{0}$, am Ende $16,5^{\circ} \mathrm{C}$.

\section{Tabelle XV.}

1. Belastung $0,25 \mathrm{gr} \quad T=1,88^{\prime \prime}$ (Mittel aus 9 Perioden)

2. " $1,0 \mathrm{gr} \quad, 1,88^{\prime \prime} \quad$ " 12 "

3. $\quad 2,0 \mathrm{gr} \quad$ gr $1,86^{\prime \prime} \quad$ " , $12 \quad$ "

4. " $4,0 \mathrm{gr} \quad$, $1,85^{\prime \prime} \quad$ ", 12 "

5. $\quad 6,0 \mathrm{gr} \quad$ " $1,83^{\prime \prime} \quad " \quad$ " $9 \quad$ "

6. $\quad 8.0 \mathrm{gr} \quad, 1,80^{\prime \prime} \quad, \quad, 3 \quad 3$

Tabelle XVI.

Dieselbe Vorkammer $1 \frac{1}{4}$ Stunde später. Temp. 16,50 C.

1. Belastung $0,5 \mathrm{gr} \quad T=1,527^{\prime \prime}$ Mittel aus 9 Perioden

2. " $1,0 \mathrm{gr} \quad$ " $1,527 " \quad, 21 \quad$ "

3. " $2,0 \mathrm{gr}, 1,512^{\prime \prime}, \quad 21$ "

4. " 4,0 gr , 1,507" ", 21 "

5. " $8,0 \mathrm{gr} \quad, 1,511^{\prime \prime}, ", 12$ "

$6 . \quad 12,0 \mathrm{gr}$ " $, 1,581 ", \quad$ " 3 "

\section{Tabelle XVII.}

Dieselbe Vorkammer, zwei Tage später, während welcher sie, immer mit dem Schreibhebel verbunden, in der feuchten hammer suspendirt gewesen war. - Temp. $18^{\circ}$.

1. Belastung $1,0 \mathrm{gr} T=3,18^{\prime \prime}$ Mittel aus 4 Perioden

2. $" 2,0 \mathrm{gr} " 3,15^{\prime \prime} \quad, \quad 4$,

3. " $4,0 \mathrm{gr} \quad 3,08^{\prime \prime} \quad$ " 4,

4. " $8,0 \mathrm{gr} \quad$ "3,11" , ", 2 " 
Eine Stunde später:

5. Belastung $1,0 \mathrm{gr} T=2,85^{\prime \prime}$ Mittel aus 4 Perioden

6. $" 2,0 \mathrm{gr} " 2,85^{\prime \prime}, " 4,4$

7. " $4,0 \mathrm{gr}, 2,82^{\prime \prime} \quad, \quad, 4 \quad \cdots "$

8. " $8,0 \mathrm{gr} \quad, 2,82^{\prime \prime} ", \quad 3 \quad$ "

Versuch vom 25. Januar 1892.

Andere Vorkammer von Rana esculenta. Vor zwei Stunden ausgeschnitten, wie die vorigen behandelt. Temperatur $18,0^{\circ} \mathrm{C}$.

Tabelle XVIII.

1. Belastung $0,75 \mathrm{gr} T=2,21^{\prime \prime}$ Mittel aus 8 Perioden

2. $" 1,5 \mathrm{gr} " 2,21^{\prime \prime} ", 8$ "

3. $, 3,0 \mathrm{gr}, 2,23^{\prime \prime} \quad$ " 8 " 8

4. " $6,0 \mathrm{gr} \quad, 2,27^{\prime \prime} \quad$ " 8 "

5. $" 12,0 \mathrm{gr} \quad, 2,29 "$ " 6 " 6

6. " $24,0 \mathrm{gr}, 2,32^{\prime \prime}$, " 2 "

Auch wenn man das ganze Herz suspendirt, sind die Erscheinungen dieselben, wofür die folgenden Versuche Beispiele bringen.

b) Einfluss verschiedener Belastung auf das Tempo der spontanen Pulsationen des in toto an der Kammerspitze suspendirten Herzens.

Versuch vom 4. Februar 1892.

R. temporaria. Curarisirt. Herz in situ. Temp. $17^{\circ}$.

Tabelle XIX.

1. Belastung 0,5 gr $T=2,00^{\prime \prime}$ Mittel aus 10 Perioden

2. $\quad 1,0 \mathrm{gr} \quad, 2,00^{\prime \prime} \quad " 10$ "

3. " $2,0 \mathrm{gr}, 2,01$ ", 10 "

4. $" 4,0 \mathrm{gr}$ " $2,01^{\prime \prime} \quad$ ", 10 "

5 . $8,0 \mathrm{gr} " 2,00 "$ " $" 5$ "

In den folgenden Versuchen ist auch das Intervall $A_{s}-V_{s}$ ausgemessen und verzeichnet.

Versueh vom 4. Oktober 1893.

R. temporaria. Kammer und Vorkammer suspendirt in feuchter Kammer $10^{\mathrm{h}} 10^{\prime}$. Anfang des Versuchs $10^{\mathrm{h}} 28^{\prime}$.

$$
\text { T abelle XX. }
$$

1. Belastung $1 \mathrm{gr} T=3,14 \boldsymbol{A}_{s}-V_{s}=0,581$ (Mittel aus 18 Perioden)

2. " $10 \mathrm{gr} \quad, 3,21 \quad$. $0,580 \quad$ " $\quad$ " 9 " Die Hubhöhe $h A$ betrug bèi $1 \mathrm{gr} \quad 3,5$, bei $10 \mathrm{gr} 0,7 \mathrm{~mm}$ " $\quad h V \quad$ " $\quad 1 \mathrm{gr} 15,5 \quad$ " $\quad 4,4$, 
Eine geringe, aber unzweifelhafte Verlängerung der spontanen Reizintervalle und dementsprechend eine deutliche Verkürzung des Zeitraums $A_{s}-V_{s}$ machte sich bei höherer Spannung bemerklich in einem

Versuch vom 3. Oktober 1893.

R. temporaria. Herz ausgeschnitten und in feuchter Kammer suspendirt. Temper. $19^{\circ} \mathrm{C}$.

\section{Tabelle XXI.}

1. Belastung 1 gr $T=1,19^{\prime \prime} A_{s}-V_{s}=0,438^{\prime \prime}$ (Mittel aus 19 Perioden

2. " $10 \mathrm{gr} \quad, 1,25 " \quad$ " $0,384^{\prime \prime} \quad$ " 9 "

Die Hubhöhe $A_{s}$ war bei $1 \mathrm{gr}$ im Durchschnitt $2,7 \mathrm{~mm}$, bei $10 \mathrm{gr} 0,6 \mathrm{~mm}$, die entsprechenden Werthe für $h V_{s} 6,5$ und $2,0 \mathrm{~mm}$.

Da in weitaus der Mehrzahl aller Fälle Unterschiede in der Belastung keinen Einfluss auf das Tempo der spontanen Pulsationen hatten, ohne gleichzeitige Aenderung der Reizpausen aber auch bei küunstlicher Reizung von $A$ das Intervall $A_{s}-V_{s}$ keine nachweisbaren Aenderungen mit der Spannung erlitt, darf auf eine Mittheilung weiterer Zahlenbelege wohl verzichtet werden.

In jedem Falle liefern unsere Versuche den Beweis, dass die sehr geringfügigen Unterschiede in der Spannung, welche die Muskelwände des Herzens bei Anwendung des Suspensionsverfahrens etwa erfahren, auf die Messungen der Leitungsgeschwindigkeit des motorischen Impulses von $A$ nach $V$ keinen störenden Einfluss ansüben können.

B. Messungender Gesehwindigkeit; mit weleher sich der Bewegungsreiz für den Ventrikeldurch di e Vorkammer fortpflanzt.

Bei den Messungen der Geschwindigkeit, mit der der Reiz für $V$ durch $A$ fortschreitet, wurde das Suspensionsverfahren in dreierlei Weise verwandt.

Erstens: Einfache Suspension des ganzen Herzens an der Kammerspitze, also gleichzeitige Registrirung von $A_{s}$ und $V_{s}$ auf derselben Curve.

Zweitens: Doppelsuspension: $A_{s}$ und $V_{s}$ mittelst eigner Hebel in der früher beschriebenen Weise jede für sich aufgezeichnet. 
Drittens: Einfache Kammersuspension: die Kammerbasis mit zwei Nadeln auf einem Korkprisma aufgesteckt, die $V$-Spitze mit Schreibhebel verbunden. $A$ auf dem Kork schwach ausgespannt mittelst der Reizelectroden, zweier Nadelpaare, die in verschiedener Entfernung von der Mitte der $V$-Basis durch die Wand von $A$ (meist von $A i$ ) gesteckt wurden.

In allen Versuchen wurde $A$ in regelmässigen, zur Erholung des Leitungsvermögens hinreichenden Intervallen abwechselnd an einer $V$ näheren und einer ferneren Stelle gereizt. Schluss und Oeffnung der Ströme besorgte das Polyrheotom mit Kupferfederoder Kupferbürstencontact. Die Reizstärke wurde im Interesse schärferer Localisirung der Reizstellen nur sehr wenig grösser genommen, als zur sicheren Erregung einer Contractionswelle eben nöthig war. Die interpolare Strecke jedes Electrodenpaars betrug etwa $1 \mathrm{~mm}$. Beim ersten und zweiten Verfahren benutzte ich entweder zwei Paar d'Arsonval'scher Silberelectroden, eventuell mit Lungenspitzen oder Froschdünndarm überzogen, oder zwei sehr kleine, leichte, nach Art von Klemmpincetten 'gebaute, bis nahe an die Spitze mit isolirendem Firniss überzogene Nickelelectroden, mit denen die Wand von $A$ an den zwei Reizstellen gefasst wird.

Das erste, einfachste Verfahren geniigt nicht ganz beim frischen, blutdurchströmten Herzen. Der Anfang von $V_{s}$ ist hier, wie schon mehrfach erwähnt, nicht scharf zu bestimmen, da er noch vor den Beginn der $A$-Diastole oder doch ungefähr auf den Gipfel der $A_{s}$ fällt. Die Leitungsgeschwindigkeit ist aber beim frischen Herzen so gross, dass Unterschiede der Latenz $\varrho A V_{s}$ bei Reizung von $A$ in verschiedener Entfernung von $V$ nur durch sehr scharfe Messungen des Anfangs von $V_{s}$ zu entdecken sein würden. Man könnte sich helfen wollen, indem man nicht den Anfang, sondern das Ende von $V_{s}$, also den Anfang von $V_{d}$, als festen Punkt benutzte, welcher Punkt hier stets sehr genau zu bestimmen ist. Dies bleibt aber darum gewagt, weil die Dauer von $V_{s}$ von der Blutfüllung abhängt, die sich an dem in situ befindlichen Herzen ändern kann.

Sehr gute Dienste leistet dagegen das erste Verfahren am ausgeschnittenen, blutleeren Herzen. Die wichtigste Thatsache, die, dass bei Reizung von $A$ in grösserer Entfernung von $V$ die $V_{s}$ erheblich später folgt als bei naher Reizung, und zwar so viel 
später, dass an Nervenleitung unmöglich gedacht werden kann, lässt sich damit ohne Messung unmittelbar anschaulich machen. Sobald sich nämlich infolge der Blutleere das Intervall $A_{s}-V_{s}$ so weit verlängert hat, dass zwischen dem Gipfel von $A_{s}$ und dem Anstieg von $V_{s}$ eine deutliche Einsenkung der Carve bemerkbar wird, zeigt sich, dass diese Einsenkung bei Reizung der ferneren Stelle steiler, tiefer und breiter ist, als bei Erregung von $A$ nahe dem Ventrikel.

Fig. 8 giebt ein Beispiel. Die Curve $8 \mathrm{a}$ ward bei Reizung in $1 \mathrm{~mm}$, Fig. $8 \mathrm{~b}$ bei Reizung in $9 \mathrm{~mm}$ Entfernung, mit nur einer halben Minute Zwischenraum, vom selben Herzen gereichnet.

Kommen spon tane, vom Si ausgehende Pulsationen in constanten Intervallen, so geben diese immer Curven von derselben Form, wie wenn $A$ weit von $V$ künstlich gereizt wurde. Hieraus folgt, dass die normalen Bewegungsreize fiu r den Ventrikel nicht in der Nähe von $V$, sondern weit davon in $A$, also vermuthlich an der Grenzevon $A$ und $S i$ ihren Ursprung nehmen, gerade wie die normale Contractionswelle in $A$.

Genaue Messungen - am besten des Intervalls $\varrho A V_{d}$, so lange der Anfang von $V_{s}$ nicht scharf zu bestimmen - bestätigen den verspäteten Eintritt von $V_{s}$ bei Reizung von $A$ in grösserem Abstand von $V$, und gestatien weitere Ermittelungen. Die Verspätung betrug in dem Fig. $8 \mathrm{~b}$ abgebildeten Falle etwa $0.09^{\prime \prime}$, woraus sich die Fortpflanzungsgeschwindigkeit des $V$-Reizes in $A$ zu etwa $90 \mathrm{~mm}$ in der Secunde berechnet. $\mathrm{Das}$ ist e in e etwa 300 Mal geringere Fortpflanzungsgeschwindigkeit als unter gleichen Bedingungen im motorischen Froschnerven.

Freilich war die Geschwindigkeit bereits unter die Norm gesunken, aber sie war auch zu Anfang des Versuchs nach directen Messungen doch immer noch weit über hundert Mal kleiner als die der Reizwelle im Nerven und sank innerhalb einer Stunde noch weit tiefer herab (s. Tab. XX).

Als Beleg sei der Verlanf des ganzen Versuchs etwas aus. führlicher mitgetheilt, da derselbe als allgemeiner Typus betrachtet werden kann. 


\section{Versuch vom 20. Mai 1892.}

Grosse männliche R. esculenta. $1^{\text {h }} 45^{\prime}$ Hirn und Rückenwark zerstört. Herz blossgelegt, Sinusligatur, Haken in Kammerspitze. Frenulum I und Aorten $1 \mathrm{~mm}$ vom Bulbus durchgetrennt. Herzwurzel oberhalb der Ligatar abgeschnitten, am Ligaturfaden festgeklemmt. Haken im Schreibhebel $0,5 \mathrm{~cm}$ von der Axe: Vergrösserung 24 mal. Belastung 1,5 gr. - Reizung durch Schliessungsinductionsschläge mit Lungenelectroden: ein Paar dicht bei $V$, das andere etwa $8 \mathrm{~mm}$ weiter davon, nahe am. Si. Reizintervall 4 Secunden. Die Reizstärke musste gegen Ende des Versuchs etwas gesteigert werden, die für die Leitungsgeschwindgkeit am Ende berechneten Werthe können infolgedessen zu gross ausgefallen sein. Vermutlich sind sie überhaupt etwas zu hoch, da die Entfernung der Stellen, von denen die Erregung wirklich ausging, aus früher besprochenen Gründen wohl etwas kleiner war als der Abstand der beiden Electrodenpaare. -- Die Cardiogramme, welche zu den Zeitmessungen dienten, warden bei einer etwa 2-3mal grösseren Geschwindigkeit der Schreibfläche als die in Fig. 8 abgebildeten aufgezeichnet. Als Chronograph diente eine Stimmgabel von 25 Schwingungen in der Secunde. Die Höhe der Curvengipfel sank im Lauf des Versuchs allmählich von 64 auf $16 \mathrm{~mm}$, das Stadium der latenten Reizung von $A$ von $0,076^{\prime \prime}$ auf $0,052^{\prime \prime}$. Letzteres war für beide Stellen von $A$ das gleiche.

Tabelle XX.

\begin{tabular}{|c|c|c|c|c|}
\hline Nr. & Zeit & $\begin{array}{l}\text { Ort der Rei- } \\
\text { zung von } A\end{array}$ & $\begin{array}{l}\rho A V_{d} \text { in } \\
\text { Secunden }\end{array}$ & $\begin{array}{l}\text { Zahl der } \\
\text { Messungen }\end{array}$ \\
\hline $\begin{array}{l}1 \\
2 \\
3\end{array}$ & $\begin{array}{r}2 \mathrm{~h} 22^{\prime} \\
24^{\prime} \\
26^{\prime}\end{array}$ & $\begin{array}{c}\text { bei } V \\
\Rightarrow S i \\
\Rightarrow V\end{array}$ & $\begin{array}{l}1,85 \\
1,90 \\
1,86\end{array}$ & $\begin{array}{l}8 \\
9 \\
8\end{array}$ \\
\hline $\begin{array}{l}4 \\
5 \\
6\end{array}$ & $\begin{array}{r}2 . \mathrm{h} 50^{\prime} \\
52^{\prime} \\
54^{\prime}\end{array}$ & $\begin{array}{ll} & S i \\
" & V \\
" & S i\end{array}$ & $\begin{array}{l}1,92 \\
1,86 \\
1,92\end{array}$ & $\begin{array}{l}9 \\
8 \\
8\end{array}$ \\
\hline $\begin{array}{l}7 \\
8 \\
9\end{array}$ & $3 \mathrm{~h} \begin{array}{l}0^{\prime} \\
2^{\prime} \\
4^{\prime}\end{array}$ & $\begin{array}{ll} & S i \\
" & V \\
" & S i\end{array}$ & $\begin{array}{l}2,03 \\
1,97 \\
2,09\end{array}$ & $\begin{array}{l}6 \\
9 \\
6\end{array}$ \\
\hline $\begin{array}{l}10 \\
11 \\
12\end{array}$ & $\begin{array}{l}16^{\prime} \\
18^{\prime} \\
20^{\prime}\end{array}$ & $\begin{array}{lc}\eta & V \\
\eta & S i \\
\eta & V\end{array}$ & $\begin{array}{l}2,10 \\
2,26 \\
2,16\end{array}$ & $\begin{array}{l}5 \\
5 \\
5\end{array}$ \\
\hline $\begin{array}{l}13 \\
14 \\
15\end{array}$ & $\begin{array}{l}24^{\prime} \\
26^{\prime} \\
28^{\circ}\end{array}$ & $\begin{array}{ll} & S i \\
" & V \\
& S i\end{array}$ & $\begin{array}{l}2,40 \\
2,22 \\
2,46\end{array}$ & $\begin{array}{l}5 \\
5 \\
5\end{array}$ \\
\hline
\end{tabular}

Es berechnet sich hiernach die Leitungsgeschwindigkeit des Reizes für $V$ innerhalb $A$ ans 


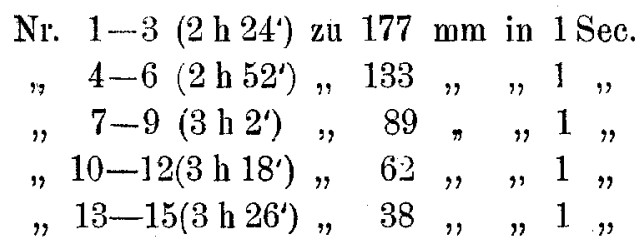

Der Versuch konnte nicht weiter fortgesetzt werden, da die Ventrikelsystolen auszubleiben anfingen.

$\mathrm{Zu}$ gleichen Ergebnissen führen die nach dem zweiten und dritten Verfahren angestellten Versuche. Sie liefern den Vortheil, dass der Anfang von $V_{s}$ sich dabei von Anfang an scharf bestimmen lässt, die in einer ungleichen Dauer von $V_{s}$ etwa gelegene Fehlerquelle sich also nicht einmischen kann.

Versuch vom 29. November 1893.

Herz einer R. esculenta mittlerer Grösse. Nicht curarisirt. $9 \mathrm{~h} \mathbf{3 5}$ ausgeschnitten, $V$ auf Kork befestigt, mit Schreibhebel verbunden. Belastung $1 \mathrm{gr}$. - Temp. $16^{\circ}$ C. -2 Paar Nadelelectroden in $A_{i}^{i}$, in etwa 3 und $7 \mathrm{~mm}$ A bstand ron der $A-V$-Grenze. Reizung in Intervallen von 6 "durch einen hinreichenden Schliessungsinductionsstrom. Zwischen je zwei Reizen wird durch einen Commutator die Reizstelle gewechselt. - Chronoskop-Stimmgabel von 10 Schwingungen in $1^{\prime \prime}$.

In Tab. XXI sind eine grössere Zahl von Einzelmessungen mitgetheilt, welche zugleicb die Breite erkennen lassen, in der die unter gleichen Bedingungen erbaltenen und gemessenen Werthe schwankten. Die zu einer Reizstelle gehörigen Werthe $\varrho A V_{s}$ sind jedesmal in eine Horizontalreibe geordnet, die gleichzeitig, alternirend, von der anderen Reizstelle aus erhaltenen in die darunter stehende Reihe. Von Zeit zu Zeit wird die Dauer der latenten Energie bei directer Reizung des Ventrikels an der Basis $\left(\varrho V_{s}\right)$ bestimmt.

\section{Tabelle XXI.}

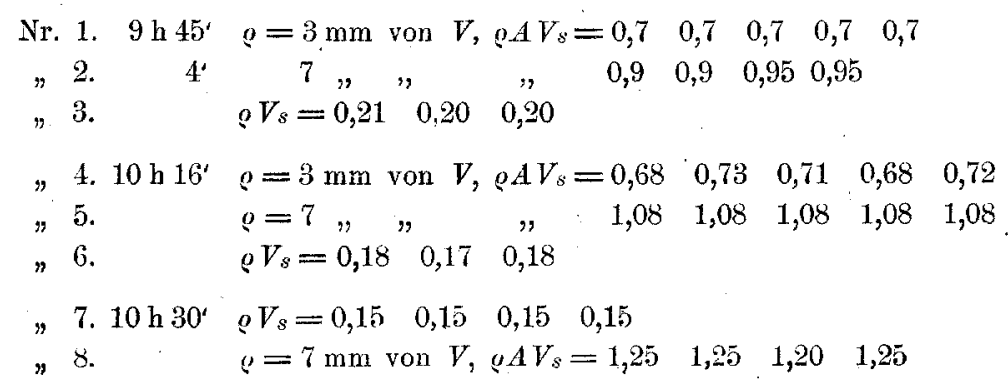




\begin{tabular}{|c|c|c|c|c|c|c|c|c|c|}
\hline Nr. $9.10 \mathrm{~h} 40^{\prime}$ & $\varrho=3 \mathrm{~mm}$ & von & $\nabla$ & $A V$ & $s=0,64$ & 0,67 & 0,73 & 0,70 & 0,74 \\
\hline 10 . & $\varrho=5$, & $n$ & $"$ & $"$ & $=0,82$ & 0,81 & 0,83 & 0,83 & 0,83 \\
\hline , 11. & $\rho=3 n$ & $"$ & $"$ & $\eta$ & $=0,74$. & 0,72 & 0,77 & 0,74 & 0,72 \\
\hline 12. & $\varrho=5$, & $"$ & $"$ & $"$ & $=0,85$ & 0,86 & 0,87 & 0,84 & 0,8 \\
\hline$" 13.10 \mathrm{~h} 55^{\prime}$ & $\varrho=3$ & $"$ & $"$ & $n$ & $=0,67$ & 0,69 & 0,67 & 0,70 & \\
\hline $\begin{array}{l}\Rightarrow 14 . \\
\Rightarrow 15 .\end{array}$ & $\begin{array}{l}\rho=5 " \\
\varrho V_{s}=0,1\end{array}$ & $4 "$ &, 15 & , & $=1,00$ & 1,00 & 0,98 & 0,99 & \\
\hline
\end{tabular}

Der erste und zweite Versuch aus Reihe 13 und der dazwischen liegende erste aus Reihe 14 sind in Fig. 9 abgebildet. Auf der mittleren Linie (Pf eil'sches Signal) sind die Reizmomente markirt.

Die Fortpflanzungsgeschwindigkeit des Bewegungsreizes für $\nabla$ innerhalb $A$ berechnet sich aus Tab. XXI

$$
\begin{aligned}
& \text { Nr. } 1-2 \cdot\left(9 \text { h } 45^{\prime}\right) \text { zu } 17,7 \mathrm{~mm} \\
& , 4-5\left(10 \mathrm{~h} 16^{\prime}\right), 10,3 \text {, } \\
& \text { " 9-10(10 h 40 }) \text { "15,6 " } \\
& \text {, 13-14(10 b 55'), 6,4 , }
\end{aligned}
$$

Die scheinbare Zunahme der Leitungsgeschwindigkeit in den Versuchen von Reihe 9 und 10 rührt wohl nur daher, dass eben zuvor die Reizstellen verändert worden waren. So lange nicht Reizstellen und Reizstärke genan dieselben bleiben, sind die Versuche nicht streng vergleichbar. Die geringe Grösse der Fortpflanzungsgeschwindigkeit schon im Anfang des Versuchs - nur ein Zehntel von der im vorigen gemessenen - findet ihre Erklärung in den viel grösseren Beleidigungen, denen bei dem Verfahren des zu Tab. XXI gehörigen Versuchs Vorkammer und auch Kammerbasis ausgesetzt werden müssen, ehe die Bestimmungen beginnen können.

Uebrigens kommen auch bei diesem Verfahren höhere Werthe der Leitungsgeschwindigkeit zur Beobachtung. So z. B. in einem zweiten

Versuch vom 29. November 1893.

Herz $12^{\mathrm{h}} 10^{\prime}$ präparirt wie das vorige, auch alles übrige gleich. Nur ist der Abstand der Electrodenpaare von der Kammergrenze resp. 3 und $8 \mathrm{~mm}$ und das Reizintervall $4^{\prime \prime}$. 
Tabelle XXII.

\begin{tabular}{|c|c|c|c|c|c|c|c|c|c|c|c|}
\hline Nr. & 1. $12 \mathrm{~h} 30^{\prime}$ & $0=3$ & $\mathrm{mmi}$ & von & $V$, & $A T$ & $s=0,57$ & 0,53 & 0,54 & 0,56 & \\
\hline , & 2. & $g=8$ & $"$ & $m$ & $"$ & $"$ & $=0,70$ & 0,73 & 0,70 & 0,70 & \\
\hline " & $33^{\prime}$ & $\varrho=3$ & $"$ & $"$ & $"$ & $n$ & $=0,54$ & 0,57 & 0,56 & 0,55 & \\
\hline$"$ & 4. & $\varphi=8$ & $"$ & $"$ & $"$ & $"$ & $=0,70$ & 0,72 & 0,72 & 0,77 & \\
\hline$"$ & $40^{\prime}$ & $\varrho=3$ & $n$ & $"$ & $"$ & $"$ & $=0,53$ & 0,53 & 0,55 & 0,53 & 0,53 \\
\hline$n$ & 6. & $\varrho=8$ & $"$ & " & $"$ & $"$ & $=0,75$ & 0,72 & 0,72 & 0,72 & 0,72 \\
\hline 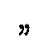 & $44^{\prime}$ & $\rho=3$ & "' & ," & , & $"$ & $=0,53$ & 0,54 & 0,54 & 0,52 & 0, \\
\hline & 8. & $\rho=8$ & $\eta$ &. & 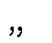 & $"$ & $=0,71$ & 0,72 & 0,72 & 0,71 & 0,70 \\
\hline
\end{tabular}

Aus den Versuchen der ersten bis vierten Reihe berechnet sich die Leitungsgeschwindigkeit in $A$ zu etwa $31 \mathrm{~mm}$, aus denen der fünften bis achten Reihe zu etwa $28 \mathrm{~mm}$.

Dass der Mangel der Bespülung mit arteriellem Blut eine der Hauptursachen, wenn nicht die wichtigste Ursache des schnellen Herabsinkens der Fortpflanzungsgeschwindigkeit von ihrem normalen Werth ist, scheint direct daraus zu folgen, dass durch Betröpfeln des ausgeschnittenen $A$ mit arteriellem Froschblut die gesunkene Geschwindigkeit merklich wieder gehoben werden kann. Es gelang mir zwar nicht, sie auf diese Weise wieder nahezu normal zu machen; aber bei der Unmöglichkeit, unter den Bedingungen des Versuchsverfahrens die Drainirung und Ernährung der Muskelsubstanz anch nur annähernd so günstig wie in der Norm zu gestalten, ist dies nur natürlich. Dass die Steigerung immerhin sehr beträchtlich sein kann, derart, dass ein Irrthum in der Deutung ausgeschlossen erscheint, lehrt $u$. a. folgender

Versueh vom 21. November 1893.

Herz von $R$. esculenta. $10_{\mathrm{h}} 40^{\prime}$ ausgeschnitten und weiter behandelt wie im vorigen Versuch. Auch alles Uebrige wie dort, soweit nichts Anderes angegeben. - Fin Electrodenpaar in etwa 2, das andere in etwa $7 \mathrm{~mm}$ Entfernung von dem Ventrikel. - Reizung in Intervallen von $7^{\prime \prime}$. Auf eine grössere Zahl Reizungen an der einen Stelle folgt jedesmal eine gleiche Zahl Reizungen an der anderen. Reizstärke für beide Stellen gleich, wenig mehr als hinreichend.

\section{Ta b ell e XXIII.}

\begin{tabular}{|c|c|c|c|c|c|c|c|c|c|c|c|}
\hline r. 1 & & $g \mathrm{~b}$ & & & & 0,90 & 0,90 & 0,94 & 0,93 & 0,96 & \\
\hline 9 & $7^{\prime}$ & $\varrho$ & $V$ & $"$ & $=0,69$ & 0,69 & 0,74 & 0,70 & 0,70 & 0,73 & 0,73 \\
\hline & $9^{\prime}$ & 0 & Si & 77 & $=1,00$ & 1,02 & 1,05 & 1,04 & 1,04 & 1,03 & 1,07 \\
\hline & $11{ }^{\circ}$ & $g$ & $V$ & $"$ & $=0,77$ & 0,77 & 0,77 & 0,77 & 0,77 & 0,78 & 0,78 \\
\hline & $13^{4}$ & 0, & $S i$ & " & $=1,09$ & 1,09 & 1,09 & 1,07 & 1,08 & & \\
\hline
\end{tabular}


Die Lieitungsgeschwindigkeit in $A$ berechnet sich hiernach zu etwa $18,5 \mathrm{~mm}$. Sie sank im Laufe weiterer 15 Minuten auf etwa $14 \mathrm{~mm}$ (Differeuz der $\varrho A V$ an den beiden Reizstellen $\left.0,35^{\prime \prime}\right)$. Es wird nun, ohne sonst etwas zu ändern, aus einer feinen Pipette arterielles Blut desselben Frosches über die auf den Kork ausgespannten Atrien geträufelt. Unmittelbar nachher und weiterhin erhält man folgende Werthe:

\section{Tabelle XXIIIa.}

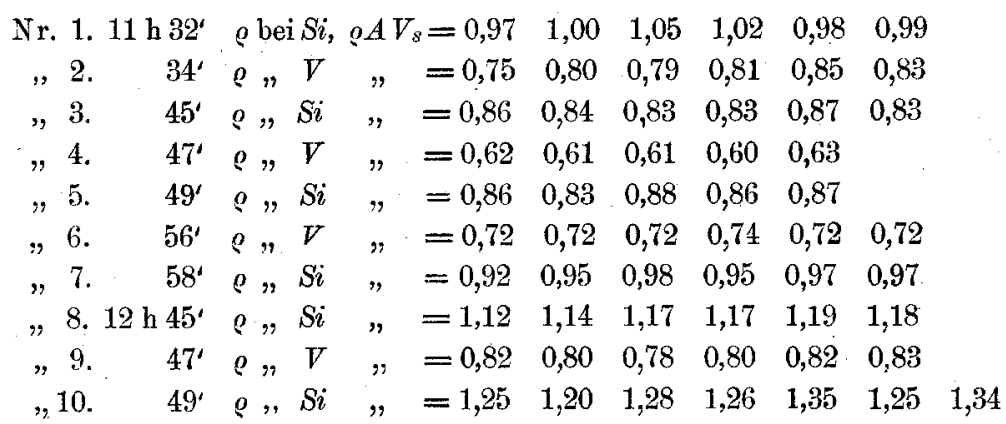

Durch das Benetzen mit Blut hebt die Geschwindigkeit der Reizleitung sich laut 1 und 2 der vorstehenden Tabelle schnell auf etwa $25 \mathrm{~mm}$, sinkt nachber wieder im Lauf einer Viertelstunde auf etwa $21 \mathrm{~mm}(3,4,5)$ und wird eine kleine Stunde später nur noch $12 \mathrm{~mm}$ gross gefunden $(8,9,10)$. Das Stadium der latenten Reizung des Ventrikels bei directer Erregung desselben an der Basis oder Spitze blieb sich, wie wiederholte Bestimmungen ergaben, während der ganzen. Versuchsdauer ziemlich gleich. Für die schwäch. sten hinreichenden Reize stieg es nicht über $0,24^{\prime \prime}$, für übermaximale Reize sank es nicht unter $0,05^{\prime \prime}$.

Aus unseren Messungen darf kein anderer Schluss gezogen werden als der :

der Reizvorgang, weleher dureh die. Vorkammer nach dem Ventrikel hin fortschreitet und diesen zur Contraction veranlasst, wird innerhalb der Vorkammer durch Muskelfasern, nicht dureh Nerven fortgeleitet. Wer jetzt noch Nervenleitung behaupten will, hat den experimentellen Nachweis zu liefern, dass es Nervenfasern beim Froseh giebt, welche unter gleichen Bedingungen die Erregung hunderte Mal langsamer als die bisher darauf untersuchten Nerven leiten. Es ist wenig Aussicht vorhanden, dass dieser Nachweis jemals geliefert werden wird. Mag man aucb nicht ohne Grund vermuthen, 
dass die Leitungsgeschwindigkeit bistiologisch rersehiedener Nervenfasern Unterschiede zeigen, die Olfactoriusfibrillen z. B. nicht mit gleicher Schnelligkeit wie gewöhnliche Muskelnerven, diese mit anderer als die $R$ e $\mathrm{mak}$ 'schen Fasern im Sympathicus die Erregung fortpflanzen, so dürfen doch auf Grund der bis jetzt bekannten Thatsachen nur relativ geringe Unterschiede erwartet werden, und immer wohl wird, auch bei weit gesunkenem Leitungsvermögen, die Gesehwindigkeit in der Secunde bei Froschnerven nach Metern, statt wie in unserem Falle beim Herzen nach Millimetern zu messen sein. Läuft doch selbst beim trägen, kaltblïtigen Hummer nach Fredericq's und Vandevelde's Untersuchnngen die Reizwelle noch mit einer Schnelligkeit von 5 -6 Metern durch den motorischen Nerven der Scheere ${ }^{1}$ ).

Die von uns für die Leitung im Vorhof gefundenen Zahlen sind dagegen durchaus von einer Ordnung mit den Werthen, welche ich selbst, M a r chand, Burdon-Sanderson und Page für die Reizleitung in den Muskelfasern des Herzventrikels vom Frosch gefunden haben. Bei den enormen Schwankungen, welche diese Werthe je nach den Versuchsbedingungen erleiden (Absterben, Ermüdung, Abkühlung u. s. w.), and bei der Sehwierigkeit, wo nicht Unmöglichkeit, dieselben beim Herzen unter ganz normalen Bedingungen zu messen, lässt sich nicht wohl entscheiden, ob die Leitung der $V$-Reize im Atrium und in der Kammer unter genau gleichen Verhältnissen wirklich gleich schnell stattfindet. Vielleicht leitet die Vorkammer schneller, da sie sich ja auch schneller contrahirt, und ist es vielleicht kein Zufall, dass ich öfter bei der blutdurchströmten Vorkammer Geschwindigkeiten ron $150-200 \mathrm{~mm}$ fand, während so hohe Werthe für die Leitung im Kammermuskel mir wenigstens beim Frosch noch nicht vorgekommen sind. Aber jedenfalls hätte ein etwaiger Unterschied für uns keine Bedeutung; da er doch im Vergleich zum Unterschied mit der Nervenleitung nur ganz geringfügig sein könnte.

Sind nun Muskelfasern der Vorkammern die Bahnen, auf welchen sich der vom Sinus kommende Reiz für $V$ nach der Kammergrenze hin durch $A$ fortpflanzt, so könne in es auch nur Muskel-

1) L. Frederiquet G. V andeve $1 \mathrm{de}$, Physiologie des muscles et des nerfs du homard. Bullet. de l'Acad. roy. de Belgique. $2^{\mathrm{m}}$ sér. t. XLVII Juni 1879. 
fasern sein, welche die Uebertragung des Reizes an der Kammergrenze von der einen auf die andere Herzabtheilung vermitteln. Wer diesem Schlus ausweichen will, muss annehmen und beweisen, dass $\operatorname{der}$ von $A$ her an der Kammergrenze innerhalb der Mnskelfasern anlangende Erregungsvorgang hier auf Nervenfasern erregend einwirkt, die durch Vermittlung von Ganglienzellen mit motorischen Nervenausläufern die Kammermuskulatur zur Contraction veranlassen, oder allenfalls, dass der von $A$ kommende Reiz von den Muskelzellen aus direct auf motorische Ganglien an der V.Grenze erregend wirkt. Die den "Block" an der Atrioventriculargrenze characterisirende Leitungsverzögerung würde jedenfalls auf Rechnung einer langen Latenz der Erregung in den Ganglienzellen zu setzen sein.

Indem ich die Mittheilung meiner diese Uebertragung des Reizes zwischen Vorkammer und Kammer betreffenden zeitmessenden Versuche einem späteren Artikel vorbehalte, will ich bier nur noch zeigen, dass bei dieser Uebertragung in keinem Falle an eine mechanische Reizung von Nerven oder Ganglien durch die sich contrahirenden Vorhofsmuskeln gedacht werden darf. Hier eben so wenig wie bei der Fortpflanzung der Erregung durch die Vorkammer und wie allgemein bei der Muskelleitung und analogen Vorgängen (Flimmerbewegung z. B.) hat der mechanische Vorgang: der Contraction etwas mit der Reizleitung zu schaffen. Es ist nieht iuberflïssig, diese fundamentale Wahrheit immer wieder zu betonen, da man noch stets entgegengesetzten Anschauungen begegnet. Hat man doch vor Kurzem sogar allen Ernstes in der mechanischen Reizung sensibler Nerven durch den Druck der sich contrahirenden Herzmuskelfasern ,die Ursache der Rhythmicität der Herzbewegungen' erkennen wollen!1) Als ob nicht längst erwiesen wäre, dass jede einzelne Herzmuskelzelle alle Bedingungen der ,Rhythmicität" schon in sich trüge!

Ich habe schon am Schluss der Einleitung einer gelegentlichen Beobachtung Erwähnung gethan, welche bewies, dass eine normale Erregung der Kammer von der Vorkammer aus zu Stande kommen kann, ohne dass dieVorkammer selbst auch nur eine Spur ron Bewegungerkennen lässt. Nachdem

1) K. Kaiser, Untersuchungen über die Ursache der Rhythmicität der Herzbewegungen. Habilitationssehrift d. Univ. Heidelberg. Münehen 1893. 
der Beweis geliefert ist, dass hierbei die Leitung nur durch Muskelfasern vermittelt gewesen sein kann, würde aus jener Beobachtung unmittelbar folgen, dass der Contractionsvorgang in den Muskelfasern der Vorkammer nicht die Ursache der Ventrikelcontraction sein kann, dass es also nicht die Contractionswelle ist, die sich als Reizwelle durch $A$ nach $V$ fortpflanzt, sondern wie im Nerven ein unsichtbarer molecularer Process; ohne Zweifel derselbe, der sich in den electrischen Bewegungserscheinungen offenbart. Es bleibt jedoch immerhin denkbar, wenn auch unwahrscheinlich, dass in jenen Versuchen die leitenden Muskelbündel sich contrahirt haben. Es ist ja bei dem eigenthizmlichen Verlauf der Muskelfaserbündel in den Vorkammern nicht wohl möglich, $A$ so za suspendiren, dass die Verkürzung eines jeden dieser Bündel zur Wirkung kommen oder auch nur im Sinne einer Hebung der Schreibspitze wirken $\operatorname{kann}^{1}$ ). Auch bedarf es theoretisch ja nur der Leitung in einer einzigen Muskelfibrille, um $V$ von $A$ ans in Erregung zu bringen. Denn erfahrungsgemäss pflanzt sich in $V$ der Reiz von jeder, auch der kleinsten Stelle nach allen anderen hin fort. Die Contraction einer einzigen oder weniger Fibrillen würde aber schwerlich unserem Schreibhebel eine merkliche Bewegung haben mittheilen können.

Mag man dies nun für übertriebenen Skepticismus halten oder nicht, erwïnscht wird es immer bleiben, Mittel zu besitzen, durch welche man in alle $\mathrm{n}$ Muskelfasern von $A$ das Contractionsvermögen aufheben kann ohne das Leitungsvermögen zu schädigen.

Ein solches Mittel scheint nach den Erfahrungen von Coats, $\mathrm{Nu}$ l, Gaskell u. a. in der Vagusreizung zu liegen. Alle Beobachter stimmen darin iberein, dass hierdurch die Vorkammersystolen fast zum Verschwinden gebracht werden können, ohne dass die Leitung der Erregung von $A$ nach $V$ aufgehoben wird. Es fehlt jeder Grund zur Annahme, dass diese contractionshemmende Wirkung sich nicht anf alle Vorkammermuskelfasern erstrecke.

Da ich mich tüberzengen wollte, ob es möglich sei, auf diesem Wege die Contractionen von $A$ wirklich völlig unmerklich zu machen ohne gleichzeitig die Fortpflanzung des $V$-Reizes durch

1) Vgl. dies Archir. Bd. 52. 1892. 8. 374. 
$A$ aufzuheben, habe ich an dem in situ, einfach oder doppelt suspendirten Herzen schwach curarisirter Frösche Reizversuche angestellt. Als das bequemste und in der Hauptsache völlig genügende Verfahren erwies sich die zuerst von $\mathrm{Budg} \mathrm{e}^{1}$ ) mit Erfolg angewandte reflectorische Reizung des Vagus von den Eingeweiden der Bauchhöhle aus. Sehr gute Resultate giebt z. B. mechanische oder electrische Reizung der Magenwand. Ich fand es nicht nöthig, die Reizbarkeit durch vorberiges längeres Blosslegen der Därme noch zu steigern.

Bei passender Wahl der Reizstärke, Reizzahl und -Frequenz gelang es leicht, die $A_{s}$ so vollkommen zum Verschwinden zu bringen, dass sie selbst bei empfindlichster Anordnung des Registrirapparats nicht, oder doch nicht sicher mehr nachweisbar waren, und ohne dass gleichzeitig die Leitung durch $A$ nach $V$ unterbrochen wurde.

Man vergleiche Fig. 10-12. In Fig. 10 (Versuch vom 15. Dez. 1891) wurde die Magenwand mechanisch, durch. Kneipen mit der Pincette gereizt. Die Reizungen sind auf der Stimmgabelcurve sichtbar, da der von der Stimmgabel zum registrirenden Tambour führende dünne Kautschukschlauch gleichzeitig von der Pincette comprimirt ward. Die Bewegungen wurden mittels eines durch die Kammerspitze gestossenen Häkchens auf den Schreibhebel übertragen.

Vor der Reizung und noch beim ersten Pulse nach Anfang der Reizung ist $A_{s}$ sehr deutlich in jedem Cardiogramm ausgeprägt, als plötzliche Knickung am Anfang des letzten Viertels des durch $V_{d}$ verursachten steilen Abstiegs. Beim zweiten Herzschlag nach Beginn der Reizung sinkt die Curve ohne Unterbrechung von $V_{a}$ vom Gipfel bis fast zur tiefsten Stelle herab, nur die Spur einer $A_{s}$ macht sich bemerkbar. Beim dritten, auch wohl beim vierten Herzschlag ist auch diese Spur zweifelhaft. Dann aber kehren die $A_{s}$ in schnell wachsender Grösse zurück: Die $V_{s}$ sind während der ganzen Zeit im gleichen Tempo wie vorher gekommen und ihr Umfang scheint dabei sogar nach der Reizung vorübergehend bedeutend gewachsen.

Noch mehr Besonderheiten - weil bei schnellerer Bewegung der Schreibfläche gezeichnet - lässt die von einem anderen Herzen gezeichnete Fig. 11 erkennen (Versuch vom 18. November 1893). Hier wurden das Mesogastrium und der Magen durch abwechselnd gerichtete mässige Inductionschläge ge-

1) J. B u d g e, Artikel Sympathischer Nerv. mit besonderer Rücksicht auf die Herzbewegung. $R$ u d. W a g $\mathrm{n}$ e $r$ 's Handwörterb. d. Physiol. Bd. III. Erste Abth. 1847, S. 427. ff.

E. Pfiuger, Archiv f. Physiologie. Ba, E6. 
reizt. Auf der mittleren Linie sind die Unterbrechungen des primären Stroms mit $P$ f e il 's Signal registrirt.

Die in der ersten Periode nach Aufhören der fast 2 Secunden anhaltenden Reizung bereits sehr geschwächte $A_{s}$ ist in der zweiten kaum mehr bemerkbar, kehrt dann schnell wachsend zurück, sodass das Cardiogramm der sechsten Periode nach Beendigung der Reizung ungefähr wieder dem letzten vor der Reizung gleicht. Die Höhe der $V_{s}$ ist dieselbe geblieben, nur ihre Form ist verändert, indem in Folge der verringerten Blutzufuhr zum. $V$ die von der plötzlichen Ausdehnung der Aorten herrührende anakrotische Erhebung wegfällt und die Daner von $V_{s}$ verkürzt ist ${ }^{1}$ ).

Das Intervall $A_{s}-V_{s}$, wie auch die Dauer von $A_{s}$ wächst infolge der Vagusreizung unverkennbar an, trotzdem gleichzeitig die Dauer der Periode - im vorliegenden Falle besonders die der zweiten nach der Reizung - merklich zugenommen hat. Scharfe Messungen sind zwar nicht möglich, aber die Ausmessung ergiebt doch, das in der zweiten und auch noch in der dritten Periode nach dem Ende der Reizung die Dauer von $A_{s}-V_{s}$ wenigstens 0,5 Stimmgabelschwingungen, d. i. wenigsten $0,05^{\prime \prime}$ mehr beträgt als vor der Reizung und am Ende des Versuchs. Ein schwächender Einfluss des Vagus auf das Fortpflanzungsvermögen der Erregung von $A$ nach $V$ ist somit im vorliegenden Falle unzweifelhaft vorhanden. Aber er ist nichtssagend im Vergleich mit der Lähmung der Contractilität von $A$.

Noch schlagender dürfte Fig. 12 (Versuch vom 18. Nov. 1893) sein. $A_{s}$ und $V_{s}$ wurden hier einzeln registrirt, $\nabla_{s}$ auf der oberen, $A_{s}$ auf der zunächst darunter gezeichneten Curve. Nach Anfang des etwa $2 \frac{1}{2}$ Secunden davernden, auf der dritten Linie mit $P f$ eils Signal registrirten Tetanisirens der Magenwand folgte erst noch eine ungeschwächte, dann eine schon auf etwa ein Drittel der normalen Höhe reducirte $A_{s}$ mit normaler $V_{s}$; auf diese, nach etwas verlängerter Panse, ohn e merkliche $A_{s}$, eine gewöhnliche $V_{s}$; der vierten $V_{s}$ geht eine fast unmerkliche $A_{s}$ voraus, danach wächst der Unifang der Contractionen von $A$ wieder, um in der neunten oder zehnten Periode nach Aufhören der Reizung wieder die anfängliche Grösse erreicht zu haben.

Das Intervall $A_{s}-V_{s}$ scheint wie im vorigen Versuch in Folge der Vagusreizung trotz Verlängerung der Perioden vorübergehend zu wachsen. Genauere Ausmessung ist nicht möglich. Jedenfalls aber ist auch hier der Einfluss anf das Leitungsvermögen verschwindend gegenüber dem auf die Contractilität.

Durch Reizung des Vagus lässt sich die Verkürzungsfähigkeit der Vorkammermuskeln immer nur auf kurze Zeit aufheben. Eine genauere Untersuchung der Leitungsverhältnisse, zu der es künstlicher periodischer Reizung bedarf, ist dadurch sehr erschwert. Es giebt aber einen Weg um die Vorkammern dauernd in einen

1) Vgl. dies Archiv Bd. 52. 1892. S. 384. 
Zustand zu versetzen, in welchem bei erhaltenem motorischen Leitungsvermögen jede Spur von Contractilität in ihnen erloschen ist. Dieser Weg ist gewiesen dureh die wichtige Entdeckung Biedermanns1), dass gewöhnliche Muskeln durch Quellung in Wasser ihres Verkürzungsvermögens völlig beraubt werden können, ohne dass electrische Reizbarkeit und Leitungsvermögen merklich beeinträchtigt $\mathrm{zu}$ sein brauchen.

Von der Richtigkeit der Thatsache hatte ich mich durch eigene Versuche am Sartorius curarisirter Frösche überzengt. Die Bestätigung ist so leicht, wie das Resultat überraschend. Der Muskel wird in der ganzen Ausdehnung, in welcher das Wasser ibn seiner Contractilität beraubt, gleichsam zum Nerv. So nun auch die Muskelbündel der Vorkammern: sie verlieren im Wasser ibren Charakter als Muskeln und behalten ihre Function als motorische Nerven der Kammer.

Ich verfuhr in der Weise, dass ich das Herz eines durch Decapitiren verbluteten Froschs an der Wurzel abschnitt, an der Ventrikelspitze suspendirte, die Vorkammern in der oben beschriebenen. Weise mit zwei, zugleich als Reizelectroden fungirenden Nadeln auf einem Korkprisma feststeckte, welches mehr oder weniger tief in die feuchte Glaskammer versenkt werden konnte. Nachdem eine Zeit lang spontane und künstlich, durch electrische Reizung von $A$, hervorgerufene Bewegungen registrirt worden waren, ward das Gefäss soweit mit Wasser gefüllt, dass Sinus und Atrien völlig unter dem Spiegel lagen, der Ventrikel aber frei herausragte. Statt des Wassers wurden öfters hypisotonische Lösungen von Kochsalz $(0,2 \%$ und weniger) genommen. Hierbei hat man den Vortheil, dass die Erscheinungen sich langsamer entwickeln, infolge davon sich genaner verfolgen lassen und dass die Grenze der Einwirkung, bei welcher auch das Leitungsvermögen schwindet, nicht so leicht erreicht wird. Mittels isotonischer oder byperisotonischer Kochsalzlösung, Blut oder Blutserum lässt sich, wie dies bei gewöhnlichen Muskeln schon Bi ed e r man $\mathbf{n}$ fand, die Contractilität wieder herstellen.

Indem ich ein näheres Eingehen auf die mannigfachen Be-

1) W. Biedermann, Ueber die Einwirkung des Aethers anf ei nige electromotorische Erscheinungen an Muskeln und Nerven. Sitzungsber. d. Akad. d. Wiss. Wien. Bd. XCVII. März 1888. S. 101. 
sonderheiten, welche bei diesen Versuchen zur Beobachtung kommen und die Besprechung wichtiger Fragen, welche sich daran anknüpfen, für eine spätere Gelegenheit aufhebe, sei hier nur das Hauptresultat an der Hand einiger Versuchsbeispiele näher dargelegt.

In Fig. 13 (Versuch vom 30. November 1893) sind sechs Stadien der Wasserwirkung abgebildet. Die obere Curve ist mittels einfacher Suspension der Kammerspitze gezeichnet; die mittlere von der Schreibspitze des Pfeil'. schen Signals gezogen, die untere giebt die Zeit in Stimmgabelschwingungen von 0,1". Die Belastung war $1,5 \mathrm{gr}$, die Hebelvergrösserung I2mal. Fig. 13a ist gezeichnet $10^{\mathrm{h}} 9^{4}$, etwa 10 Minuten nach dem Herausschneiden and dem Suspendiren des Herzens: die $A_{s}$ sind sehr gross, die $V_{s}$ kleiner, abwechselnd eine kleiner und eine grösser, das Intervall $A_{s}-V_{s}$ misst etwa $0,7^{\prime \prime}$. Um 10 12', fünf Minuten vor Fig. $13 \mathrm{~b}$ wird Kochsalzlösung von $0,1 \%$ eingefüllt, bis $S i$ völlig und $A$ fast bis an die $V$-Grenze untergetaucht sind. Das Tempo der spontanen Pulsationen nimmt ab, in Folge davon wächst die Grösse der $V_{s}$, während die $A_{s}$ alsbald sehr in Umfang vermindern. Die vier ersten Systolen von $A$ und $V$ in Fig. $13 \mathrm{~b}$ sind durch electrische Reizung von $A$ in etwa $5 \mathrm{~mm}$ Entfernung von $V$ hervorgerufen, die letate ist automatischen Ursprungs. Das Stadium $\rho A_{s}$ beträgt etwa $0,1^{\prime \prime}, \varrho A V_{s}$ etwa $1^{\prime \prime}$, also $A_{s}-V_{s}$ etwa $0,9^{\prime \prime}$. Fig. $13 \mathrm{c}\left(10^{\mathrm{h}} 27^{\prime}\right)$ zeigt die Contractilität von $A$ weiter vermindert, $\nabla_{s}$ ungeschwächt (wegen Verlängerung der Pausen). Die Dauer $\varrho A V_{s}$ hat auf etwa $1,3^{\prime \prime}$ zugenommen, was nicht auf die Wasserwirkung geschoben werden darf, da, wie früher gezeigt, die gleiche Zunahme schon in Folge des blossen Herausschneidens und Verblutens eintritt. Bemerkenswerth aber ist, und scheinbar in Streit mit unserer früheren Angabe von der relativen Unveränderlichkeit des Stadiums directer latenter Reizung von $A$, das relativ viel beträchtlichere Wachsthum von $\varrho A_{s}$. Dies Stadium beträgt in Fig. $13 \mathrm{c}$ wenigstens $0,35^{\prime \prime}$. Der Grund hiervon liegt einfach darin, dass die Reizstelle von $A$ weit von $V$ lag und $A_{s}$ hauptsächlich nur noch von dem unmittelbar an $V$ grenzenden Theil von $A$ herührrt, der etwas über dem Wasserspiegel hervorragte und desshalb weniger rasch seine Contractilität einbüsste. Noch deutlicher wird der Unterschied in Fig. 13 d, $10^{\mathrm{h}} 36^{\mathrm{A}}$ gezeichnet. Hier ist $\varrho A_{s}$ in der ersten Periode etwa $0,5^{\prime \prime}$, in der zweiten etwa $1,1^{\prime \prime}$, während das Intervall $A_{s}-V_{s}$ sogar erheblich kürzer erscheint als in Fig. 13a-c. In Fig. $13 \mathrm{e}\left(10^{\mathrm{b}} 50^{\circ}\right)$ ist vollends $A_{s}$ bis auf eine minimale, kaum noch merkliche Erhebung am Fusse von $V_{s}$ reducirt. $\varrho A_{s}$ scheint verlängert auf etwa $1,4^{\prime \prime}, A_{s}-V_{s}$ ist verkürzt auf etwa $0,57^{\prime \prime}$. In Fig. $13 \mathrm{f}\left(10^{\text {h }} 48^{\prime}\right)$ ist jede Spur von $A_{s}$ getilgt, $\varrho A V_{s}$ auf etwa 2 Sec. gewachsen. Die $V_{s}$ sind nur wenig kleiner geworden. Das Stadium directer latenter Reizung von $V$ betrug zur selben Zeit ungefähr $0,15^{\prime \prime}$.

Ein ähnlicher Versuch (vom 5. Dez. 1893), in welchem auch die Rückkehr der Contractilität von $A$ durch stärkere Salzlösungr 
kenntlich, ist noch in Fig. 14 theilweise abgebildet. Hier wurde nicht nur der ganze $A$, sondern auch die Basis von $V$ bis auf etwa $0,5-1 \mathrm{~mm}$ von der $A$-Grenze unter $\mathrm{NaCl} 0,1 \%$ getaucht. Die Erscheinungsweise der Wasserwirkung ist darum etwas anders. Zwar verschwinden die $A_{s}$ auch völlig, aber ohne dass das Stadium $\varrho A_{s}$ eine so erhebliche scheinbare Verlängerung zeigt wie im vorigen Versuch. Die Ventrikelcontractionen erscheinen infolge der Quellung der Ventrikelbasis verlängert.

Den Verlauf der Aenderungen in den Latenzstadien und den Verkürzungsgrössen $h A_{s}$ und $h V_{s}$ geben näher die in Tab. XXIV zusammengestellten Messungen. Die in Fig. 14 abgebildeten Stadien entsprechen den folgenden Zeitpunkten des Versuchs: Fig. 14 a $: 11^{\mathrm{h}} 25^{\prime}$, b : $11^{\mathrm{h}} 36^{\mathrm{f}}$, c: $11^{\mathrm{h}} 57^{\mathrm{t}}, \mathrm{d}: 12^{\mathrm{h}} 10^{\text {, }}$, e $: 12^{\mathrm{h}} 36^{\circ}, \mathrm{f}: 12^{\mathrm{h}} 47^{\mathrm{f}}, \mathrm{g}: 1^{\mathrm{h}} 8^{\mathrm{c}}$. Der Frosch (mittelgrosse $\mathrm{R}$. temporaria) war um 12 Uhr durch Decapitiren und Verbluten getödtet, das Herz an der Wurzel ausgeschnitten, $A$ mit zwei Nadelelectroden auf dem Korkprism befestigt, $V$ spitze suspendirt. Belastung $1 \mathrm{gr}$, Vergrösserung $12 \mathrm{mal}$. Abstand der Electroden von der $V$-Grenze etwa $5 \mathrm{~mm}$. Von $11^{\mathrm{h}} 24^{\prime}$ bis $12^{\mathrm{h}} 26^{\circ}$ hingen $\mathrm{Si}, \mathrm{A}$ und $V$-Basis unter $\mathrm{NaCl} 0,1^{\%} \%, 12^{\mathrm{h}} 27^{\prime}$ warde die dünnere Salzlösung durch ein Gemisch von 20 Theilen $\mathrm{NaCl} 1 \%$ und 1 Theil mit Luft geschüttelten Froschbluts ersetzt. Die Temperatur blieb während des ganzen Versuchs etwa auf $13^{\circ} 5 \mathrm{C}$. - Eine Stimmgabel von 25 Schwingungen in $1^{\prime \prime}$ registrirte die Zeit. In der Tabelle sind die gemessenen Werthe in Sekunden umgerechnet.

Tabelle XXIV.

\begin{tabular}{r|r|c|c|c|c|c}
\hline \hline Nr. & Zeit & $T$ & $\varrho A_{s}$ & $\varrho A V_{s}$ & $\begin{array}{c}h A_{s} \\
\mathrm{~mm}\end{array}$ & $\begin{array}{c}h V_{s} \\
\mathrm{~mm}\end{array}$ \\
\hline & $\mathbf{1 1 h} 22^{\prime}$ & 1,60 & 0,12 & 0,68 & 7,6 & $\mathbf{1 2 , 5}$ \\
2 & $26^{\prime}$ & 2,08 & 0,12 & 0,80 & 7,6 & 15,0 \\
3 & $28^{\prime}$ & 2,08 & 0,13 & 0,80 & 7,5 & $\mathbf{1 5 , 0}$ \\
4 & $35^{\prime}$ & 2,08 & 0,12 & 0,72 & 5,9 & 15,6 \\
5 & $40^{\prime}$ & 2,08 & 0,13 & 0,80 & 5,4 & 18,0 \\
6 & $45^{\prime}$ & 2,08 & 0,13 & 0,80 & 4,7 & 18,5 \\
7 & $50^{\prime}$ & 2,04 & 0,14 & 0,84 & 3,8 & 18,5 \\
8 & $55^{\prime}$ & 2,04 & 0,16 & 0,88 & 2,8 & 18,0 \\
9 & $12 \mathrm{~h} 0^{\prime}$ & 2,40 & 0,19 & 0,96 & 2,6 & 18,5 \\
10 & $5^{\prime}$ & 2,80 & 0,18 & 1,04 & 0,9 & 18,0 \\
11 & $10^{\prime}$ & 2,80 & - & 1,04 & 0,3 & 16,5 \\
12 & $15^{\prime}$ & 2,80 & - & 1,16 & 0,2 & 18,0 \\
13 & $30^{\prime}$ & 2,80 & - & 1,04 & 0,0 & 22,0 \\
$\mathbf{1 4}$ & $35^{\prime}$ & 2,80 & - & 1,06 & 0,0 & 20,0 \\
15 & $40^{\prime}$ & 3,24 & - & 1,16 & 0,3 & 18,5 \\
16 & $45^{\prime}$ & 3,24 & 0,28 & 1,20 & 0,8 & 16,0 \\
17 & $50^{\prime}$ & 3,20 & 0,26 & 1,24 & 1,0 & 14,5 \\
18 & $55^{\prime}$ & 2,60 & 0,27 & 1,28 & 1,3 & 13,0 \\
19 & $1 \mathrm{~h} 5^{\prime}$ & 2,60 & 0,28 & 1,42 & 1,6 & 13,0 \\
20 & $10^{\prime}$ & 2,60 & 0,30 & 1,44 & 2,2 & 12,5
\end{tabular}


202 Th. W. Engelmann: Beobachtungen u. Versuche an suspendirten Herzen.

Man bemerke, dass im vorstehenden Versuch das anfängliche Wachsen von $\varrho A V_{s}$ nach Beginn der Wassereinwirkung vorïbergehend zum Stillstand kommt, ja selbst einer Abnahme Platz macht. In vielen Fällen war diese Beschleunigung der motorischen Leitung durch $A$ nach $V$ unter Einwirkung von Wasser noch weit auffälliger. Ich unterlasse aber die nähere Besprechung dieser Fälle, da es für den vorliegenden Zweck nicht darum zu thun ist, die Wirkung des Wassers auf Leitungsvermögen und Contractilität in allen Richtungen zu schildern, sondern nur um den Nachweis, dass die Muskelfasern der Vorkammer auch nach vollständiger Aufhebung ihrer Contractilität doch den Bewegungsreiz für den Ventrikel noch fortzupflanzen im Stande sind, und zwar mit einer Geschwindigkeit durchaus derselben Ordnung, wie wenn das Verkürzungsvermögen erhalten wäre. 